\title{
Is formal thought disorder in schizophrenia related to structural and functional aberrations in the language network?
}

\section{A systematic review of neuroimaging findings}

Marialuisa Cavelti ${ }^{\mathrm{a} b}$, Tilo Kircher ${ }^{c}$, Arne Nagels $^{c}$, Werner Strik ${ }^{\mathrm{a}}$, Philipp Homan ${ }^{\text {a/d }}$ *

a Translational Research Center, University Hospital of Psychiatry and Psychotherapy, University of Bern, 3000 Bern 60, Switzerland.

${ }^{\mathrm{b}}$ Orygen, The National Centre of Excellence in Youth Mental Health \& Centre for Youth Mental Health, University of Melbourne, Parkville, VIC 3052, Australia.

c Department of Psychiatry and Psychotherapy, University of Marburg, Rudolf-Bultmann-Strasse 8, 35039 Marburg, Germany.

${ }^{d}$ Department of Psychiatry, and Friedman Brain Institute, Icahn School of Medicine at Mount Sinai, New York, NY 10029, USA.

* Corresponding author: homan@puk.unibe.ch

Manuscript word account: 4463

Abstract word account: 250

Key words account: 6

Tables and figures: 7 


\section{ABSTRACT}

Formal thought disorder (FTD) is a core feature of schizophrenia, a marker of illness severity and a predictor of outcome. The underlying neural mechanisms are still a matter of debate. This study aimed at 1) reviewing the literature on the neural correlates of FTD in schizophrenia, and 2) testing the hypothesis that FTD correlates with structural and functional aberrations in the language network.

Medline, PsychInfo, and Embase were searched for neuroimaging studies, which applied a clinical measure to assess FTD in adults with schizophrenia and were published in English or German in peer-reviewed journals until December 2016.

Of 412 articles identified, 61 studies were included in the review. Volumetric studies reported bilateral grey matter deficits $(\mathrm{L}>\mathrm{R})$ to be associated with FTD in the inferior frontal gyrus, the superior temporal gyrus and the inferior parietal lobe. The same regions showed hyperactivity in resting state functional magnetic resonance imaging (fMRI) studies and both hyper- and hypoactivity in fMRI studies that employed semantic processing or free speech production tasks. Diffusion tensor imaging studies demonstrated white matter aberrations in fibre tracts that connect the frontal and temporo-parietal regions.

FTD in schizophrenia was found to be associated with structural and functional aberrations in the language network. However, there are studies that did not find an association between FTD and neural aberrations of the language network and regions not included in the language network have been associated with FTD. Thus, future research is needed to clarify the specificity of the language network for FTD in schizophrenia.

Keywords: Preferred Reporting Items for Systematic reviews and Meta-Analyses guidelines (RPISMA), speech, communication, disorganization, disorganized, psychosis 


\section{Abbreviations}

AF Arcuate Fascicle

AG Angular Gyrus

ASL Arterial Spin Labeling

BA Brodmann Area

BOLD Blood-Oxygen-Level Dependent

BPS Bern Psychopathology Scale

CBF Cerebral Blood Flow

CT Computer Tomography

DTI Diffusion Tension Imaging

FA Fractional Anisotropy

fMRI functional Magnetic Resonance Imaging

FOp Frontal Operculum

FTD Formal Thought Disorder

GM Grey Matter

HC Healthy Controls

HG Heschl's Gyrus

IFG Inferior Frontal Gyrus

ILF Inferior Longitudinal Fascicle

IFOF Inferior Fronto-Occipital Fascicle

IPL Inferior Parietal Lobe

MdLF Middle Longitudinal Fascicle

MRI Magnetic Resonance Imaging

MTG Middle Temporal Gyrus

PET Positron Emission Tomography

RDoC Research Domain Criteria

PRISMA Preferred Reporting Items for Systematic reviews and Meta-Analyses

ROI Region Of Interest

SLF Superior Longitudinal Fascicle

SMG Supramarginal Gyrus 
SMRI structural Magnetic Resonance Imaging

SPECT Single Photon Emission Computer Tomography

STG Superior Temporal Gyrus

STS Superior Temporal Sulcus

SZ Schizophrenia

TALD Thought And Language Disorder Scale

UF Uncinate Fascicle

WM White Matter 


\section{Introduction}

Formal thought disorder (FTD) is a core symptom of schizophrenia. 'Formal' refers to aberrations in the thought process in contrast to aberrations in the thought content (i.e., delusions). As FTD affects the thought process as well as thought expression, it is defined as a severe language and speech disturbance (Hart and Lewine, 2017). It occurs in the general population (Rossler et al., 2013), in relatives of patients with schizophrenia (Morgan et al., 2017), in people at high risk of developing psychosis (Demjaha et al., 2012; Katsura et al., 2014), as well as in patients with non-affective psychoses, affective psychoses, and nonpsychotic disorders (Nagels et al., 2016). Prevalence rates, which are dependent on the assessment method used, are highest in schizophrenia (50-80\%), followed by schizoaffective disorders $(60 \%)$, depression $(53 \%)$, and healthy controls $(6 \%)$. The results regarding the prevalence in mania are mixed, with some studies reporting higher rates and other studies reporting lower or similar rates than in schizophrenia (Roche et al., 2015). Therefore, FTD should be considered as both a dimensional entity of language pathology and a categorical entity in terms of a trait marker for psychosis (Roche et al., 2015). Further, FTD is multidimensional and has been distinguished into quantitative (e.g., speed of speech, poverty of content of speech) and qualitative (e.g., neologisms, semantic and phonemic paraphasia), objective (e.g., observer-rated circumstantiality, cross-talk) and subjective (e.g., self-reported inhibited thinking, pressure / rush of thought), and positive (e.g., derailment, tangentiality) and negative (e.g., poverty of thought, thought blocking) forms (Kircher et al., 2014; Strik et al., 2010). For illustrative speech examples of patients with FTD, see Andreasen (1979). Usually, FTD is assessed by clinician-based rating scales, which demonstrated adequate psychometric properties and clinical utility (for an overview about commong ratings scales, see Hart and Lewine, 2017). Recently, the usage of alternative approaches such as behavioural coding of communication failures, computational linguistic methods and or ambulatory recording technologies have been proposed in order to overcome the limitations of the traditional clinical scales (e.g., questionable inter-rater reliability, low ecological validity; Cohen et al., 2017; Elvevag et al., 2017). Positive and negative FTD have distinct neuropsychological (Nagels et al., 2016; Tan and Rossell, 2017) and neurobiological correlates (Palaniyappan et al., 2015; Sans-Sansa et al., 2013), and negative FTD proved to be a better predictor of clinical and functional outcome than positive FTD (Roche et al., 2015). Overall, FTD is disabling, limiting symptomatic remission (Yalincetin et al., 2016b), social and occupational functioning (Tirupati et al., 2004; Yalincetin et al., 2016b), wellbeing and life satisfaction (Sigaudo et al., 2014; Tan et al., 2014), and therapeutic relationship and psychological recovery (Cavelti et al., 2016).

Language processing is served by cortical and subcortical cerebral networks. Disturbed communication within and between brain regions of the language network may constitute the neurobiological underpinnings of FTD (Kircher, 2008; Strik et al., 2008). Being aware that the neural network underlying human language comprises multiple and widespread regions throughout the brain, "Language network" traditionally refers to the inferior frontal gyrus (IFG; approx. Brodmann Area (BA) $44,45,47$ ), the frontal operculum (FOp), the superior temporal gyrus (STG; approx. BA 22, 38, 41, 42), the middle temporal gyrus (MTG; approx. BA 21, 37), the superior temporal sulcus (STS) and the inferior parietal lobe (IPL; approx. BA 39, 40) of both hemispheres ( $\mathrm{P}>\mathrm{R}$; see Figure 1). Additional 
cortical regions across the brain are recruited for language perception (i.e., sensory input systems such as the auditory system (Heschl's gyrus ( $\mathrm{HG}$ ) in the superior temporal lobe for hearing and the visual system (visual word form area) in the temporo-occipital region for reading) and speech production (i.e., premotor cortex and supplementary motor area in the frontal lobe for articulation), respectively (Price, 2010). The communication between the grey matter (GM) regions of the language network is accomplished by white matter (WM) fibre bundles. The frontal and temporo-parietal language regions are connected by a dorsal and ventral pathway, respectively (Friederici, 2011; Hickok and Poeppel, 2007). The dorsal pathway includes the arcuate fascicle (AF) and the superior longitudinal fascicle (SLF), while the inferior fronto-occipital fascicle (IFOF) and the uncinate fascicle (UF) are major fibre tracts of the ventral pathway (Chang et al., 2015; Friederici, 2011). Additional WM tracts involved in language processing are the middle longitudinal fascicle (MdLF), which connects anterior and posterior temporal regions, and the inferior longitudinal fascicle (ILF), which connects the temporal pole to the occipital lobe (Chang et al., 2015) (for a more detailed description of the anatomy of the language network we refer to excellent reviews by Price (2010) and Friederici (Friederici, 2011, 2012; Friederici and Gierhan, 2013)).

Strik et al. (2008) proposed that in periods of increased demands for communication performance (e.g., during critical life events or transitions into the next stage of life), GM deficits in temporo-parietal regions of the left hemisphere (Horn et al., 2010) may trigger a dysfunction in the bilateral language network, including the IFG, STG and IPL (Horn et al., 2009; Horn et al., 2012; Stegmayer et al., 2017). This dysfunction of the language network may be mediated by aberrations in WM tracts of the language network (UF, SLF, ILF, IFOF) and the corpus callosum, which is the major connection between the two hemispheres of the brain (Viher et al., 2016b). As a result of these structural and functional aberrations, FTD emerges, leading to communication difficulties in social situations. Recent advances in neuroimaging technology allow the testing of such hypotheses by the unprecedented investigation of the FTD symptoms in vivo.

In light of the growing number of studies examining FTD in schizophrenia with neuroimaging techniques, the current study was aimed at 1) systematically reviewing the literature on the neural correlates of FTD, and 2) testing the hypothesis that FTD in schizophrenia correlates with structural and functional aberrations in the language network (Kircher, 2008; Strik et al., 2008). Previous reviews have addressed epidemiology and phenomenology, conceptualization and measurement, cognitive processes, semantic priming abnormalities, linguistics and genetics of FTD in schizophrenia (Cohen et al., 2017; Covington et al., 2005; DeLisi, 2001; Hart and Lewine, 2017; Kerns and Berenbaum, 2002; Kircher, 2008; Kuperberg, 2010a, b; Leube et al., 2008; Levy et al., 2010; Pomarol-Clotet et al., 2008; Radanovic et al., 2013; Roche et al., 2015; Sumner et al., 2017; Wensing et al., 2017; Yalincetin et al., 2016a). A comprehensive systematic review of the neural correlates, including both structural and functional aberrations, of FTD in schizophrenia is yet missing. In the present review we summarize neuroimaging studies of FTD in schizophrenia, following the Preferred Reporting Items for Systematic reviews and Meta-Analyses (PRISMA) guidelines (Moher et al., 2015). We chose to examine associations between structural and functional aberrations in the language system and FTD rather than schizophrenia as an entity, because we believe that a symptom specific approach is more 
promising. In addition, being aware that FTD encompasses various cognitive and linguistic functions, we chose to stick with that umbrella term because of its clinical utility. 


\section{Methods}

\subsection{Selection criteria}

Studies were included if meeting the following eligibility criteria: (1) recruitment of adult patients diagnosed with schizophrenia; (2) application of neuroimaging, including computer tomography (CT), positron emission tomography (PET), single photon emission computer tomography (SPECT), structural magnetic resonance imaging (sMRI), functional magnetic resonance imaging (fMRI), diffusion tension imaging (DTI), and arterial spin labeling (ASL); (3) the assessment of FTD by a clinical measure; (4) the report of associations between imaging results and the presence or severity of FTD; and (5) published in a peer-reviewed English or German journal.

\subsection{Search strategy}

A comprehensive search from the electronic databases MEDLINE (PubMed.gov interface, 1966December 2016), Embase (OvidSP interface, 1974-December 2016), and PsycINFO (OvidSP interface, 1806-December 2016) was conducted. The relevant studies were identified using the following combination of key words: 'schizophrenia' OR 'psychosis' AND 'thought disorder/s' OR 'formal thought disorder/s' OR 'disorganized speech' OR 'speech disorganization' OR 'disorganized language' OR 'language disorder/s' AND 'neuroimaging' OR 'computer tomography' OR 'positron emission tomography' OR 'single photon emission computer tomography' OR 'magnetic resonance' OR 'functional magnetic resonance' OR 'diffusion tensor imaging' OR 'arterial spin labeling'. No search limits other than time (until December 2016) and language (English, German) were set. The electronic database search was supplemented by searching through references, recent reviews (Leube et al., 2008; Rapp and Steinhauser, 2013; Sun et al., 2009), and a book chapter (Nagels and Kircher, 2016).

The literature search was conducted separately by the first and last author. They independently screened the titles and abstracts of records, eliminated duplicates, worked through the full texts if necessary, and decided whether the remaining records met the eligibility criteria. Then they compared the results of their independent searches, resolved disagreements through discussion, and reached to a final decision regarding the inclusion of studies in this review.

\subsection{Data extraction}

The variables of interest to be extracted from the studies were study design, participants (groups, numbers), sex, age, diagnosis, duration of illness, antipsychotic medication, assessment tool of FTD, imaging technique, type of functional imaging study (resting state, task-based), imaging scope (region of interest (ROI) or whole brain), a priori ROls, and imaging outcome measure (for fMRI studies global and regional blood-oxygen-level dependent (BOLD) signal; for PET, SPECT, and ASL studies the global and regional cerebral blood flow (CBF); for CT and SMRI studies the global and regional brain volumes, and for DTI studies fractional anisotropy (FA). The data extraction was independently conducted by the first and last author. The results were compared and disagreements were resolved by discussion.

2.4. Study quality evaluation 
The quality of the included studies was evaluated in terms of statistical power (i.e., sample size) and the multidimensional assessment of FTD (i.e., the differentiation between positive and negative FTD). These two criteria were selected for the following reasons: First, low power of imaging studies has been discussed as by far the most concerning issue in neuroscience (e.g. Button et al., 2013). Second, it is very unlikely that symptoms as different as derailment and thought blocking share the same neurobiological underpinnings (e.g. Sumner et al., 2017). The sample sizes of studies were categorized as following: $1=<15$ participants per group, $2=15-30$ participants per group, $3=>30$ participants per group. However, it should be noted that even with a sample size of more than 30 participants, the effect sizes needed for a finding to be significant at a significance level of 0.05 and to be detectable with a statistical power of $80 \%$ are still fairly large $(\mathrm{d}=0.72$ for an independent-samples $\mathrm{t}$ test, $4=.048$ for a between-subjects correlation; Cohen, 1988). When the group sizes of a study fell into two different categories, a conservative approach was chosen and the smaller category was reported. The assessment of FTD of studies was categorized as 1 , if it was unidimensional (i.e., "overall FTD", positive or negative FTD only), and as 2 if it was multidimensional (i.e., positive and negative forms differentiated). Summing up the scores of the two criteria, a total score of 5 was considered to be quality A (good), a score of 4 to be quality B (medium), and a score of 3 or 2 to be quality $\mathrm{C}$ (poor). 


\section{Results}

The search strategy identified 412 articles (see Figure 2). After excluding 154 duplicates, 258 articles were screened for eligibility. One hundred and ninety-seven articles were excluded, according to the following reasons: No adults ( $n=9)$, no schizophrenia diagnosis $(n=41)$, no neuroimaging $(n=15)$, no (clinical) assessment of FTD ( $n=78)$, association between imaging and FTD not examined $(n=10)$, no original articles $(n=32)$, journal not peer-reviewed $(n=1)$, language not English or German $(n=4)$, and case study $(n=7)$. Sixty-one studies met the eligibility criteria. The included studies were grouped according to the neuroimaging technique into structural $(n=41)$ and functional studies $(n=23)$. Three studies reported both structural and functional results (Horn et al., 2009; Skudlarski et al., 2010; Weinstein et al., 2007). The included studies involved a total number of 1582 patients with schizophrenia (SZ; 1254 males, 327 females, 1 missing) and 1280 healthy controls (HC; 961 males, 319 females). In patients, duration of illness ranged between 5.2 months and 20.2 years, indicating that the included studies covered patients from early to chronic stages of the disorder. While few studies did not report the medication status (Arnedo et al., 2015; DeLisi and Hoff, 2005; DeLisi et al., 1994; Dieci et al., 1998; Holinger et al., 1999; Petty et al., 1995b; Vita et al., 1995), all but three (DeLisi et al., 1989; Sabri et al., 1997; van Veelen et al., 2011) examined patients treated with antipsychotics and all but three studies (DeLisi and Hoff, 2005; Sabri et al., 1997; Takahashi et al., 2011) reported cross-sectional findings.

As the included studies were highly diverse with regard to the comparison groups, FTD measurement, experimental tasks used in FRMI studies, scanner types and setups, imaging outcome measures, and methods of imaging analysis, a quantitative synthesis (meta-analysis) did not seem appropriate for the current investigation. In addition, the information needed to compute effect sizes was not always available. For these reasons, we decided to conduct a qualitative synthesis. This was done in two steps: First, in accordance with the first aim of the review (i.e., providing an overview about the neural correlates of FTD in schizophrenia), we summarized the methods and results of all studies included in the review in the Tables 1-4. Second, in accordance with the second aim of the review (i.e., testing the hypothesis that FTD in schizophrenia manifests as a result of structural and functional aberrations in the language network), we picked only those studies that examined either the whole brain or the language network as ROI, and counted the number of studies that found an association between FTD and neural aberrations in the language network as defined in Figure 1 (i.e., IFG, FOp, STG, MTG, STS, IPL) compared to the number of studies that did not (see Figure 3). Both steps were done separately for SMRI, DTI, resting-state fMRI and task-based fMRI studies. The three studies reporting both structural and functional findings (Horn et al., 2009; Skudlarski et al., 2010; Weinstein et al., 2007) were considered twice for the summaries given in the tables and Figure 3. If the study design included three groups (HC, schizophrenia patients with FTD (SZ-FTD), schizophrenia patients without FTD (SZ-nFTD), only the differences between the patient groups are presented in the tables, because differences between HC and SZ patients could be due to other factors than FTD such as general aspects of pathology or medication. We did not consider overlapping samples between studies, as our primary goal was to give a comprehensive qualitative overview of current research on neural correlates of FTD in schizophrenia. 


\subsection{Structural imaging studies}

\subsubsection{Volumetric studies (Table 1)}

Imaging studies examining GM correlates of FTD reported volume deficits in the language network (see Figure 3, top left chart). Concerning the frontal regions of the language network, this includes the left FOp (Sans-Sansa et al., 2013) and the left (Dieci et al., 1998; Sans-Sansa et al., 2013) and bilateral (Palaniyappan et al., 2015; Vita et al., 1995) IFG. Notably, Palaniyappan et al. (2015) reported FTD to be correlated with an increased volume of the IFG. Additionally, there are studies that did not find any association between FTD and GM volumes in the lateral frontal lobe (Horn et al., 2010; Horn et al., 2009; Marsh et al., 1997; Nestor et al., 1998; Yamasue et al., 2004). Concerning the temporo-parietal regions of the language network, volume deficits were found in the left (Horn et al., 2010; Horn et al., 2009; Rajarethinam et al., 2000; Sans-Sansa et al., 2013; Shenton et al., 1992) or bilateral (Anderson et al., 2002; Barta et al., 1997; Marsh et al., 1997; Palaniyappan et al., 2015; Subotnik et al., 2003; Weinstein et al., 2007) STG (including the temporal pole and the planum temporale), the left STS (Horn et al., 2010; Horn et al., 2009), and the left AG (Horn et al., 2009). Notably, associations between FTD and increased volumes of the left (Dieci et al., 1998) and right (Holinger et al., 1999; Vita et al., 1995) STG as well as non-significant associations of FTD with volumes of the STG (DeLisi and Hoff, 2005; DeLisi et al., 1994; Meisenzahl et al., 2004; Menon et al., 1995; Sallet et al., 2003; Shapleske et al., 2001; Yamasue et al., 2004) and the IPL (Niznikiewicz et al., 2000) have also been reported. In addition, FTD was associated with decreased or reversed asymmetries of the planum temporale (normal asymmetry left larger than right) in two studies (Petty et al., 1995a; Rossi et al., 1994), while another study did not find such an association (DeLisi et al., 1994). Increased leftwards asymmetry of the horizontal Sylvian fissure was also found to be associated with FTD (Shapleske et al., 2001). However, a subgroup of patients with auditory hallucinations accounted for the latter finding.

Additionally, FTD has been found to be associated with GM volume deficits in cortical regions outside the traditional language network. This includes the orbitofrontal cortex (Horn et al., 2010; Nakamura et al., 2008; Sans-Sansa et al., 2013), the ventromedial prefrontal cortex (Sans-Sansa et al., 2013), the middle, medial, and superior frontal gyri (Palaniyappan et al., 2015), the precuneus (Horn et al., 2009; Palaniyappan et al., 2015), the insula (Palaniyappan et al., 2015; Yamasue et al., 2004), the cingulate gyrus (Horn et al., 2009; Palaniyappan et al., 2015) (a non-significant finding was reported by Yamasue et al. (2004)), and the cuneus/lingual gyrus (Horn et al., 2010). Also, increased volumes of the parahippocampal gyrus (Anderson et al., 2002) and both decreased and increased volumes of the cerebellum (Kuhn et al., 2012; Levitt et al., 1999) have been reported to be significantly correlated with FTD.

Finally, studies examining GM correlates of FTD in subcortical areas reported inconsistent findings for the hippocampus-amygdala complex (Anderson et al., 2002; Elfaki et al., 2016; Fukuzako et al., 1996; Marsh et al., 1997; Rajarethinam et al., 2001; Sallet et al., 2003; Subotnik et al., 2003), the basal ganglia (Nestor et al., 1998; Palaniyappan et al., 2015), and the ventricular system (Dieci et al., 1998; Sallet et al., 2003; Shenton et al., 1991; Vita et al., 1995). No association was found between FTD and 
the GM volume of the thalamus (Portas et al., 1998). In a longitudinal study, pituitary enlargement over time (mean 2.7 years) was associated with more severe FTD at follow-up (Takahashi et al., 2011).

In sum, the current evidence indicates that GM deficits in the language network are associated with FTD in schizophrenia. Even if this is the finding of the review that got the most empirical support, we still found negative findings as well as reports of correlations between brain volume increases and FTD. Further, FTD in schizophrenia seems not to be exclusively related to aberrations of the language network, as additional correlates with GM deficits in cortical regions outside the language network, such as the orbitofrontal cortex, the precuneus, the insula, and the cingulate gyrus, have been reported. The results for the involvement of subcortical areas in FTD in schizophrenia are mixed or based on single studies only, calling for further research.

\subsubsection{DTI studies (Table 2)}

Imaging studies examining WM alterations as correlates of FTD reported reduced fractional anisotropy (FA) in major tracts of the language network (see Figure 3, bottom left chart), including the left MdLF (Asami et al., 2013), the bilateral SLF, the bilateral IFOF, the left IFL, and the left UF (Viher et al., 2016b).

FTD was also associated with FA reductions in additional WM tracts, including the cingulum bundle (Bopp et al., 2016), the corpus callosum, the internal and external capsule (Arnedo et al., 2015; Viher et al., 2016b), the fornix (Arnedo et al., 2015), the corona radiata, the thalamic radiation, the forceps minor and the corticospinal tract (Viher et al., 2016b). In the study by Bijanki et al. (2015), FA across the cerebrum was positively correlated with FTD, but became non-significant after controlling for age. Skudlarski et al. (2010) reported a negative correlation between FTD and structural connectivity across the whole brain. Viher et al. (2016a) found significant associations of WM integrity with negative symptoms and abnormal psychomotor behaviour, but not with FTD.

In sum, while the number of DTI studies is still small, there is increasing evidence suggesting that FTD in schizophrenia is associated with reduced WM integrity in both, major tracts of the language network and major tracts across the whole brain.

\subsection{Functional imaging studies}

\subsubsection{Resting state studies (Table 3)}

Imaging studies examining resting state activity as a correlate of FTD reported hyperperfusion in the language network (see Figure 3, bottom right chart), including the left (Horn et al., 2009) and bilateral (Sabri et al., 1997) IFG, the left (Horn et al., 2009) and bilateral (DeLisi et al., 1989; Sabri et al., 1997) STG, the bilateral MTG (DeLisi et al., 1989; Sabri et al., 1997), the left AG (Horn et al., 2009) and the bilateral IPL (Sabri et al., 1997). In contrast, Liemburg et al. (2012) did not find any association between FTD and resting state activity in the IFG and STG. Skudlarski et al. (2010) found FTD to be associated with greater spatial coherence between resting state and WM connectivity in the Task Positive Network that includes inferior frontal, middle temporal and inferior parietal brain regions.

Additionally, FTD has been found to be associated with altered resting state activity in cortical regions that are outside the traditional language network, including the insula (Horn et al., 2009; Skudlarski et 
al., 2010) and the cingulate gyrus (Sabri et al., 1997; Skudlarski et al., 2010). However, Liemburg et al. (2012) did not find an association between FTD and resting state activity in the cingulate gyrus.

Finally, FTD was not related to resting state activity in subcortical brain regions such as the thalamus and the basal ganglia (Sabri et al., 1997), but to increased resting state connectivity between the thalamus and the left postcentral gyrus (Skudlarski et al., 2010).

In sum, current resting state studies most clearly indicate that FTD in schizophrenia is associated with hyperperfusion in regions of the language network. The evidence regarding the associations with altered resting state activity in cortical regions outside the traditional language network and in subcortical regions is less consistent.

\subsubsection{Tasked-based functional studies (Table 4)}

Imaging studies examining neural activity during a cognitive task in the scanner as a correlate of FTD assessed outside the scanner reported the involvement of the language network (see Figure 3, top right chart), including the IFG (left > right), the STG (left > right), the MTG (left > right), the left STS, the right SMG and the $A G$. In the following the study results are described in more detail, separately for each type of task.

Irony comprehension. One study examined brain activity while participants read ironic and literal text vignettes and reported FTD to be associated with hyperactivity in the right STG, the left posterior cingulate gyrus and the left thalamus during irony comprehension (Rapp et al., 2013).

Passive language perception. In two studies by the same research group (Weinstein et al., 2006; Weinstein et al., 2007), participants listened to English (comprehensible), Mandarin (noncomprehensible), and reversed English (control) speech while being in the scanner. FTD was associated with hyperactivity in the left STG, the left STS and the left MTG during listening to comprehensible speech.

Free speech production. Five studies examined brain activity while participants were prompted to speak about Rorschach inkblots or pictures of the Thematic Association Test by Murray (1943). They reported an association between FTD and altered activity (mostly hypoactivity in the left hemisphere and hyperactivity in the right hemisphere) in the language network, including the bilateral IFG pars orbitalis (McGuire et al., 1998), the left (Kircher et al., 2003; Kircher et al., 2001b; Matsumoto et al., 2013; McGuire et al., 1998) and right (Kircher et al., 2002) STG, the left (Kircher et al., 2002; Kircher et al., 2001b) and right (Kircher et al., 2003; Kircher et al., 2002; McGuire et al., 1998) MTG, the left (Kircher et al., 2003) and right (Matsumoto et al., 2013) AG, and the right SMG (Kircher et al., 2003). Additionally, FTD correlated with altered activation (both hypo- and hyperactivity) in cortical regions that are outside the traditional language network, such as the middle frontal gyrus (Kircher et al., 2003; McGuire et al., 1998), the cingulate gyrus (Kircher et al., 2003; Matsumoto et al., 2013; McGuire et al., 1998), the precuneus (Kircher et al., 2002), the insula (McGuire et al., 1998), the precentral gyrus (Kircher et al., 2001b), the fusiform gyrus (Kircher et al., 2003; Kircher et al., 2002; McGuire et al., 1998), the parahippocampal gyrus (McGuire et al., 1998) and the post-cerebellar cortex (Kircher et al., 2002). Finally, FTD was associated with altered activation in non-cortical areas, including the caudate 
nucleus (Kircher et al., 2001b; McGuire et al., 1998), the corpus callosum, the cuneus (Kircher et al., 2003) and the cerebellum (Kircher et al., 2003; Kircher et al., 2002; Kircher et al., 2001b).

Semantic processing. Ten studies applied an experimental task that elicited semantic processing in order to examine brain activity associated with FTD. Altered activity (both hypo- and hyperactivity) in the language network were reported, including the left IFG (Arcuri et al., 2012; Chen et al., 2013; Horn et al., 2012; Kircher et al., 2001a), the right STG (Kircher et al., 2001a), and the left (Kircher et al., 2001a) and bilateral (Kuperberg et al., 2007) MTG. However, there were studies that did not find any association between FTD and activity in the language network during semantic processing (Assaf et al., 2006; Jamadar et al., 2013; Kircher et al., 2008; van Veelen et al., 2011). Altered activity (both hypo- and hyperactivity) in cortical regions that are outside the traditional language network found to be associated with FTD include the middle (Arcuri et al., 2012) and superior (Ragland et al., 2008) frontal gyri, the cingulate gyrus (Arcuri et al., 2012; Assaf et al., 2006; Ragland et al., 2008), the fusiform gyrus (Kuperberg et al., 2007; Ragland et al., 2008), the lingual gyrus (Kircher et al., 2008; Ragland et al., 2008), the insula (Kircher et al., 2001a), the postcentral gyrus (Kircher et al., 2001a), the superior parietal gyrus (Ragland et al., 2008), the precuneus (Kircher et al., 2001a) and the cuneus (Ragland et al., 2008).

In sum, functional studies examining the association between neural activity and FTD in schizophrenia used various cognitive tasks, which makes the comparison of the results across the studies difficult. The majority of the studies used a task, which required either the production of free speech or the processing of semantic material. Both groups of studies reported altered activity in a wide range of brain regions, which included, but were not limited to the language network (e.g., the IFG, STG, and MTG).

\subsection{Quality of included studies}

As shown in Table 5, 3 of 61 studies (3.28\%) were considered as being of good quality (A), 13 studies (21.31\%) as being of medium quality (B), and 46 studies $(75.41 \%)$ as being of low quality $(C)$ in terms of statistical power and the multidimensional assessment of FTD. With regard to criterion 1, 13 of 61 studies $(21.31 \%)$ showed adequate statistical power, 32 studies $(52.46 \%)$ showed medium statistical power, and 16 studies (26.23\%) showed low statistical power. With regard to criterion 2, 4 of 61 studies $(6.56 \%)$ applied a multidimensional FTD measure, and 57 studies (93.44\%) applied a unidimensional FTD measure. 


\section{Discussion}

The current study systematically reviewed neuroimaging studies from 1966 until December 2016 that examined neural correlates of FTD in schizophrenia. We identified 61 studies suitable for inclusion. Despite the strict eligibility criteria applied, a striking finding of this review is the heterogeneity of current research in terms of methodology and, consequently, of findings. This made a formal statistical comparison of the results impossible. Nevertheless, several important findings emerged from our review:

Structural studies reported bilateral GM deficits in the language network, in particular, encompassing the bilateral IFG, the left FOp, the bilateral STG, the left STS and the left AG, as correlates of FTD. In addition, they showed a diminished asymmetry of the planum temporale (left > right) to be associated with FTD, indicating a decrease of the normal hemispheric lateralization of the language network. The majority of resting state $\mathrm{fMRI}$ studies suggested hyperactivity in the bilateral language network (left > right), specifically in the IFG, the STG, the MTG and the IPL, to be related to FTD. Also, the bilateral language network (left > right), in particular, the IFG, the STG, the MTG, the STS and the IPL, showed altered neural activation (both hypo- and hyperactivity) during irony comprehension, passive language perception, free speech production, and semantic processing tasks in fMRI studies to be associated with FTD. Taken together, this review revealed FTD in schizophrenia to be associated with aberrations in GM structure and neural activity of cortical regions involved in language processing. Middle and superior temporal gyri and sulci are involved in prelexical and semantic processing of single words and sentences, while inferior frontal areas and the AG accomplish top-down semantic, syntactic and articulatory constraints (Price, 2010).

This review also found evidence for altered GM structure (mostly volume loss) and neural activity (both hypo- and hyperactivity) in cortical regions outside the traditional language network that are involved in language processing, such as the middle and superior frontal gyri, the insular cortex, the cingulate gyrus, the precentral gyrus, the cuneus/lingual gyrus, the fusiform gyrus, the parahippocampal gyrus and the cerebellum. These brain regions are more specifically associated with aspects of speech production, i.e., word retrieval, inhibitory control, articulatory planning and auditory self-monitoring (Price, 2010). Finally, the few DTI studies to date demonstrated WM aberrations (mostly FA reductions) in major fibre tracts of the language network, including the bilateral SLF, the bilateral IFOF, the left UF and the left MdLF. The former tract is part of the dorsal pathway subserving auditory-tomeaning mapping, while the latter three tracts are part of the ventral pathway supporting auditory-tomotor-mapping (Chang et al., 2015; Friederici, 2012; Hickok and Poeppel, 2007). In addition, the finding of reduced FA in the corpus callosum associated with FTD indicates an interaction deficit between hemispheres and supports the idea of a diminished language lateralization in schizophrenia patients with FTD (Nagels and Kircher, 2016).

Taken together, this review found some support for the hypothesis that the language network is involved in FTD in schizophrenia, which we consider as moderate in size for the following reasons (Kircher, 2008; Strik et al., 2008). First, there are studies that did not find an association between FTD and structural or neural aberrations of the language network (see Figure 3). However, the sample size of the majority of studies was below the number of participants required ( $<30$ participants per group), 
to detect an intermediate effect with $80 \%$ at a 0.05 significance level. This may have contributed to the lack of association between FTD measures and imaging results. Second, regions not included in the traditional language network have been associated with FTD. Also, many of the included studies used whole-brain approach, which results in regions surviving a statistical threshold. This, however, does not mean that the regions not surviving that threshold are not engaged or unimportant (Yarkoni, 2009). The difference between "significant" regions and "non-significant" regions is in general not a distinction that allows one to conclude that the significant but not the non-significant regions are the relevant ones (Gelman and Stern, 2006). In other words, specificity for a region can in general not be established with conventional whole brain analyses. Therefore, the conclusion of the specificity of the language network for FTD should be considered with caution. Interestingly, the cortical circuits found to be associated with FTD in this review show a substantial overlap with those that have been linked to auditory verbal hallucinations (AVH) (Curcic-Blake et al., 2015; Hubl et al., 2004). This supports the idea that FTD and AVH are both related to structural and functional aberrations of the language network, but that the individual pattern of the involved network components may determine the psychopathological phenomenon (Strik et al., 2008). Overall, our results are to a considerable degree consistent with a most recent meta-analysis of functional correlates (Wensing et al., 2017) and a systematic review of the structural correlates (Sumner et al., 2017) of FTD in schizophrenia. The neural networks found to be associated with FTD in schizophrenia seem to be primarily involved in auditory and language processing, and to a lesser degree in higher order cognitive processes (i.e., executive functions, working memory, social cognition).

This review demonstrated a high level of heterogeneity of findings across studies. On the one hand, this can be explained by the multidimensionality of FTD and the involvement of different components of the language network in different language functions. On the other hand, it reflects several methodological differences and limitations of the research conducted to date. First, only a minority of the study (21\%) showed adequate statistical power, defined as a sample size of $>30$ participants per group. Second, the samples were disproportionately male, both for patients and HC. Third, the remarkable progress in computational precision in neuroimaging over the last decades limits the comparison of findings from older and more recent studies. Fourth, the patient samples varied markedly across studies with regard to duration of illness, general symptomatology, FTD severity and medication status. Fifth, the majority of the included fMRI studies applied experimental tasks that elicited semantic processing, thereby ignoring other linguistic domains (i.e., auditory sensory, phonology, morphology, articulation, syntax and pragmatics). In addition, the majority of experimental tasks relied on passive speech perception and only a few involved active speech production. Sixth, various measures were applied to assess FTD, which differed in their conceptualization of the phenomenon and ranged from a single item to complex sum scales. The majority of these measures capture positive FTD or overall FTD. Thus, only $6.5 \%$ of all included studies applied a multidimensional FTD measure. In particular, only few studies to date have examined neural correlates of negative FTD as opposed to positive FTD (Arnedo et al., 2015; Kircher et al., 2003; Palaniyappan et al., 2015; Sans-Sansa et al., 2013; Viher et al., 2016b). In addition, the included studies only considered observed FTD, ignoring self-reported dysfunction in language perception and speech production (Kircher et al., 2014). Recently developed measures, such as the Thought and 
Language Disorder (TALD) scale (Kircher et al., 2014) and the Bern Psychopathology Scale (BPS) (Strik et al., 2010), thus, include objective and subjective as well as positive and negative aspects of FTD.

There are a number of limitations to our review. First, although the systematic procedure applied is one of its strengths, it is still possible that we excluded articles that contain interesting information regarding neural correlates of FTD in schizophrenia. For instance, we excluded studies that measured disorganized speech and disorganized behaviour as part of the same syndrome (Nagels and Kircher, 2016) so as not to confound results. Second, our review excluded studies that assessed FTD by computational linguistic tools that objectively quantify normative features of speech samples and may be more reliable than approaches based on clinical impression (Tagamets et al., 2014; Willits et al., 2017). Third, our review did neither consider the effect of different illness stages (i.e., first episode psychosis versus chronic schizophrenia) nor of neuroleptic medication on neural correlates of FTD (Dietsche et al., 2017). Forth, given the current data situation, the chosen qualitative approach of this review seems to be most adequate to get an overview. However, qualitative reviews do not represent the best scientific evidence and include some crucial shortcomings. For instance, we were not able to quantify the strength of the relationship between FTD and neural correlates. Further, we did not assess the risk of meta-biases such as publication bias across studies (Moher et al., 2015). Fifth, given the lack of universal criteria defining "high quality studies", we used a quality index to evaluate the risk of bias of individual studies that considered statistical power and multidimensional assessment of FTD. This quality index helped to identify major limitations of the research up to date, but was far from being comprehensive. Finally, the umbrella term "FTD", on which our review was based, is commonly used when working with patients, but covers various cognitive and linguistic functions. This might have contributed to the heterogeneity of findings.

Based on the findings of this review, the following recommendations for future research can be made: First, the field would clearly benefit from multidimensional assessments of FTD with concurrent investigation of sub-syndromes or single symptoms. FTD should be conceptualized as a dimensional construct, for instance within in the Research Domain Criteria (RDoC) language construct (Cohen et al., 2017). When using clinical rating scales to assess FTD, researchers should at least differentiate between positive and negative FTD (Roche et al., 2015; Yalincetin et al., 2016a). Also, new technologies (i.e., naturalistic behavioural sampling techniques, computational modelling) could be used in order to overcome some of the limitations of the clinical measures. Second, the specificity of language dysfunctions for FTD compared to other schizophrenia domains could be examined by employing language production and perception tasks in patients with varying degrees of FTD expression. Third, longitudinal studies would allow for the assessment of interactions between neural structural and functional changes, FTD development and outcome over time. Finally, clinical trials could test the potential therapeutic impact of modulating the affected brain regions by means of noninvasive brain stimulation, for instance with transcranial magnetic stimulation.

In conclusion, despite the apparent heterogeneity of FTD neuroimaging findings, this systematic review found moderate support for the structural and functional involvement of the language network 
in FTD in schizophrenia. In addition, it refers to the necessity of further investigating how specific structural and functional aberrations of the language network are for FTD in schizophrenia. 


\section{References}

Anderson, J.E., Wible, C.G., McCarley, R.W., Jakab, M., Kasai, K., Shenton, M.E., 2002. An MRI study of temporal lobe abnormalities and negative symptoms in chronic schizophrenia. Schizophr Res 58(2-3), 123-134.

Andreasen, N.C., 1979. Thought, language, and communication disorders. I. Clinical assessment, definition of terms, and evaluation of their reliability. Arch Gen Psychiatry 36(12), 1315-1321.

Arcuri, S.M., Broome, M.R., Giampietro, V., Amaro, E., Jr., Kircher, T.T., Williams, S.C., Andrew, C.M., Brammer, M., Morris, R.G., McGuire, P.K., 2012. Faulty suppression of irrelevant material in patients with thought disorder linked to attenuated frontotemporal activation. Schizophrenia Res Treatment 2012, 176290.

Arnedo, J., Mamah, D., Baranger, D.A., Harms, M.P., Barch, D.M., Svrakic, D.M., de Erausquin, G.A., Cloninger, C.R., Zwir, I., 2015. Decomposition of brain diffusion imaging data uncovers latent schizophrenias with distinct patterns of white matter anisotropy. Neuroimage 120, 43-54.

Asami, T., Saito, Y., Whitford, T.J., Makris, N., Niznikiewicz, M., McCarley, R.W., Shenton, M.E., Kubicki, M., 2013. Abnormalities of middle longitudinal fascicle and disorganization in patients with schizophrenia. Schizophr Res 143(2-3), 253-259.

Assaf, M., Rivkin, P.R., Kuzu, C.H., Calhoun, V.D., Kraut, M.A., Groth, K.M., Yassa, M.A., Hart, J., Jr., Pearlson, G.D., 2006. Abnormal object recall and anterior cingulate overactivation correlate with formal thought disorder in schizophrenia. Biol Psychiatry 59(5), 452-459.

Barta, P.E., Pearlson, G.D., Brill, L.B., 2nd, Royall, R., McGilchrist, I.K., Pulver, A.E., Powers, R.E., Casanova, M.F., Tien, A.Y., Frangou, S., Petty, R.G., 1997. Planum temporale asymmetry reversal in schizophrenia: replication and relationship to gray matter abnormalities. Am J Psychiatry 154(5), 661 667.

Bijanki, K.R., Hodis, B., Magnotta, V.A., Zeien, E., Andreasen, N.C., 2015. Effects of age on white matter integrity and negative symptoms in schizophrenia. Schizophr Res 161(1), 29-35.

Bopp, M.H., Zollner, R., Jansen, A., Dietsche, B., Krug, A., Kircher, T.T., 2016. White matter integrity and symptom dimensions of schizophrenia: A diffusion tensor imaging study. Schizophr Res 184, 5968.

Button, K.S., loannidis, J.P., Mokrysz, C., Nosek, B.A., Flint, J., Robinson, E.S., Munafo, M.R., 2013. Power failure: why small sample size undermines the reliability of neuroscience. Nat Rev Neurosci 14(5), 365-376.

Cavelti, M., Homan, P., Vauth, R., 2016. The impact of thought disorder on therapeutic alliance and personal recovery in schizophrenia and schizoaffective disorder: An exploratory study. Psychiatry Res 239, 92-98.

Chang, E.F., Raygor, K.P., Berger, M.S., 2015. Contemporary model of language organization: an overview for neurosurgeons. J Neurosurg 122(2), 250-261.

Chen, P.J., Fan, L.Y., Hwang, T.J., Hwu, H.G., Liu, C.M., Chou, T.L., 2013. The deficits on a corticalsubcortical loop of meaning processing in schizophrenia. Neuroreport 24(3), 147-151.

Cohen, A.S., Le, T.P., Fedechko, T.L., Elvevag, B., 2017. Can RDoC Help Find Order in Thought Disorder? Schizophr Bull 43(3), 503-508.

Cohen, J., 1988. Statistical power analysis for the behavioral sciences., 2nd ed. Lawrence Erlbaum Associates, Hillsdale, NJ.

Covington, M.A., He, C., Brown, C., Naci, L., McClain, J.T., Fjordbak, B.S., Semple, J., Brown, J., 2005. Schizophrenia and the structure of language: the linguist's view. Schizophr Res 77(1), 85-98. 
Curcic-Blake, B., Nanetti, L., van der Meer, L., Cerliani, L., Renken, R., Pijnenborg, G.H., Aleman, A., 2015. Not on speaking terms: hallucinations and structural network disconnectivity in schizophrenia. Brain Struct Funct 220(1), 407-418.

DeLisi, L.E., 2001. Speech disorder in schizophrenia: review of the literature and exploration of its relation to the uniquely human capacity for language. Schizophr Bull 27(3), 481-496.

DeLisi, L.E., Buchsbaum, M.S., Holcomb, H.H., Langston, K.C., King, A., Kessler, R., Pickar, D., Carpenter, W.T., Morihisa, J.M., Margolin, R., Weinberger, D.R., 1989. Increased temporal lobe glucose use in chronic schizophrenic patients. Biol Psychiat 25(7), 835-851.

DeLisi, L.E., Hoff, A.L., 2005. Failure to find progressive temporal lobe volume decreases 10 years subsequent to a first episode of schizophrenia. Psychiatry Res 138(3), 265-268.

DeLisi, L.E., Hoff, A.L., Neale, C., Kushner, M., 1994. Asymmetries in the superior temporal lobe in male and female first-episode schizophrenic patients: measures of the planum temporale and superior temporal gyrus by MRI. Schizophr Res 12(1), 19-28.

Demjaha, A., Valmaggia, L., Stahl, D., Byrne, M., McGuire, P., 2012. Disorganization/cognitive and negative symptom dimensions in the at-risk mental state predict subsequent transition to psychosis. Schizophr Bull 38(2), 351-359.

Dieci, M., Tenconi, F., Gimosti, E., Ferri, S., Salmoiraghi, A., Severino, G., Vita, A., 1998. Brain morphological multidetermination of langauge and thought disorders in schizophrenia. New Trends Exp Clin Psychiat 14(2), 99-102.

Dietsche, B., Kircher, T., Falkenberg, I., 2017. Structural brain chagnes in schizophrenia at different stages of the illness: A selective review of longitudinal magnetic resonance imaging studies. Aust N Z J Psychiatry 51(5), 500-508.

Elfaki, A., Ali, T.O., Osman, A.M., Gudek, M.A., Golpinar, M., Erkan, I., B., S., 2016. Right-left and sex dependent differences of hippocampus and amygdala sizes and their relation to the clinical symptoms of schizophrenia: a comparative brain segmentation study. Folia Medica - Facultatis Medicinae Universitatis Saraeviensis 51(2), 62-69.

Elvevag, B., Foltz, P.W., Rosenstein, M., Ferrer, I.C.R., De Deyne, S., Mizraji, E., Cohen, A., 2017. Thoughts About Disordered Thinking: Measuring and Quantifying the Laws of Order and Disorder. Schizophr Bull 43(3), 509-513.

Friederici, A.D., 2011. The brain basis of language processing: from structure to function. Physiol Rev 91(4), 1357-1392.

Friederici, A.D., 2012. The cortical language circuit: from auditory perception to sentence comprehension. Trends Cogn Sci 16(5), 262-268.

Friederici, A.D., Gierhan, S.M., 2013. The language network. Curr Opin Neurobiol 23(2), 250-254.

Fukuzako, H., Fukazako, T., Hashiguchi, T., Hokazono, Y., Takeuchi, K., Hirakawa, K., Ueyama, K., Takigawa, M., Kajiya, Y., Nakajo, M., Fujimoto, T., 1996. Reduction in hippocampal formation volume is caused mainly by its shortening in chronic schizophrenia: assessment by MRI. Biol Psychiatry 39(11), 938-945.

Gelman, A., Stern, H., 2006. The Difference Between "Significant" and "Not Significant" is not Itself Statistically Significant. Am Stat 60(4), 328-331.

Harrow, M., Quinlan, D.M., 1985. Disordered Thinking and Schizpohrenic Psychopathology. Gardner Press, New York.

Hart, M., Lewine, R.R., 2017. Rethinking Thought Disorder. Schizophr Bull, doi: 10.1093/schbul/sbx003. 
Hickok, G., Poeppel, D., 2007. The cortical organization of speech processing. Nat Rev Neurosci 8(5), 393-402.

Holinger, D.P., Shenton, M.E., Wible, C.G., Donnino, R., Kikinis, R., Jolesz, F.A., McCarley, R.W., 1999. Superior temporal gyrus volume abnormalities and thought disorder in left-handed schizophrenic men. Am J Psychiatry 156(11), 1730-1735.

Horn, H., Federspiel, A., Wirth, M., Muller, T.J., Wiest, R., Walther, S., Strik, W., 2010. Gray matter volume differences specific to formal thought disorder in schizophrenia. Psychiatry Res 182(2), 183186.

Horn, H., Federspiel, A., Wirth, M., Muller, T.J., Wiest, R., Wang, J.J., Strik, W., 2009. Structural and metabolic changes in language areas linked to formal thought disorder. $\mathrm{Br} J$ Psychiatry 194(2), 130 138.

Horn, H., Jann, K., Federspiel, A., Walther, S., Wiest, R., Muller, T., Strik, W., 2012. Semantic network disconnection in formal thought disorder. Neuropsychobiology 66(1), 14-23.

Hubl, D., Koenig, T., Strik, W., Federspiel, A., Kreis, R., Boesch, C., Maier, S.E., Schroth, G., Lovblad, K., Dierks, T., 2004. Pathways that make voices: white matter changes in auditory hallucinations. Arch Gen Psychiatry 61(7), 658-668.

Jamadar, S., O'Neil, K.M., Pearlson, G.D., Ansari, M., Gill, A., Jagannathan, K., Assaf, M., 2013. Impairment in semantic retrieval is associated with symptoms in schizophrenia but not bipolar disorder. Biol Psychiatry 73(6), 555-564.

Katsura, M., Ohmuro, N., Obara, C., Kikuchi, T., Ito, F., Miyakoshi, T., Matsuoka, H., Matsumoto, K., 2014. A naturalistic longitudinal study of at-risk mental state with a 2.4 year follow-up at a specialized clinic setting in Japan. Schizophr Res 158(1-3), 32-38.

Kerns, J.G., Berenbaum, H., 2002. Cognitive impairments associated with formal thought disorder in people with schizophrenia. J Abnorm Psychol 111(2), 211-224.

Kircher, T., 2008. [Neurobiological foundations of thought and language disorder in schizophrenia]. Fortschr Neurol Psychiatr 76 Suppl 1, S24-32.

Kircher, T., Krug, A., Stratmann, M., Ghazi, S., Schales, C., Frauenheim, M., Turner, L., Fahrmann, P., Hornig, T., Katzev, M., Grosvald, M., Muller-Isberner, R., Nagels, A., 2014. A rating scale for the assessment of objective and subjective formal Thought and Language Disorder (TALD). Schizophr Res 160(1-3), 216-221.

Kircher, T., Liddle, P., Brammer, M., Murray, R., McGuire, P., 2003. [Neural correlates of "negative" formal thought disorder]. Nervenarzt 74(9), 748-754.

Kircher, T., Whitney, C., Krings, T., Huber, W., Weis, S., 2008. Hippocampal dysfunction during free word association in male patients with schizophrenia. Schizophr Res 101(1-3), 242-255.

Kircher, T.T., Bulimore, E.T., Brammer, M.J., Williams, S.C., Broome, M.R., Murray, R.M., McGuire, P.K., 2001a. Differential activation of temporal cortex during sentence completion in schizophrenic patients with and without formal thought disorder. Schizophr Res 50(1-2), 27-40.

Kircher, T.T., Liddle, P., Brammer, M., Williams, S., Murray, R., McGuire, P., 2002. Reversed lateralization of temporal activation during speech production in thought disordered patients with schizophrenia. Psychol Med 32(3), 439-449.

Kircher, T.T., Liddle, P., Brammer, M.J., Williams, S.C., Murray, R.M., McGuire, P.K., 2001b. Neural correlates of formal thought disorder in schizophrenia: Preliminary findings from a functional magnetic resonance imaging study. Arch Gen Psychiat 58(8), 769-774.

Kuhn, S., Romanowski, A., Schubert, F., Gallinat, J., 2012. Reduction of cerebellar grey matter in Crus I and II in schizophrenia. Brain Struct Funct 217(2), 523-529. 
Kuperberg, G.R., 2010a. Language in schizophrenia Part 1: an Introduction. Lang Linguist Compass 4(8), 576-589.

Kuperberg, G.R., 2010b. Language in schizophrenia Part 2: What can psycholinguistics bring to the study of schizophrenia...and vice versa? Lang Linguist Compass 4(8), 590-604.

Kuperberg, G.R., Deckersbach, T., Holt, D.J., Goff, D., West, W., 2007. Increased temporal and prefrontal activity in response to semantic associations in schizophrenia. Arch Gen Psychiat 64(2), 138-151.

Leube, D., Whitney, C., Kircher, T., 2008. The neural correlates of ego-disturbances (passivity phenomena) and formal thought disorder in schizophrenia. Eur Arch Psychiatry Clin Neurosci 258 Suppl 5, 22-27.

Levitt, J.J., McCarley, R.W., Nestor, P.G., Petrescu, C., Donnino, R., Hirayasu, Y., Kikinis, R., Jolesz, F.A., Shenton, M.E., 1999. Quantitative volumetric MRI study of the cerebellum and vermis in schizophrenia: clinical and cognitive correlates. Am J Psychiatry 156(7), 1105-1107.

Levy, D.L., Coleman, M.J., Sung, H., Ji, F., Matthysse, S., Mendell, N.R., Titone, D., 2010. The Genetic Basis of Thought Disorder and Language and Communication Disturbances in Schizophrenia. J Neurolinguistics 23(3), 176.

Liemburg, E.J., Vercammen, A., Ter Horst, G.J., Curcic-Blake, B., Knegtering, H., Aleman, A., 2012. Abnormal connectivity between attentional, language and auditory networks in schizophrenia. Schizophr Res 135(1-3), 15-22.

Marsh, L., Harris, D., Lim, K.O., Beal, M., Hoff, A.L., Minn, K., Csernansky, J.G., DeMent, S., Faustman, W.O., Sullivan, E.V., Pfefferbaum, A., 1997. Structural magnetic resonance imaging abnormalities in men with severe chronic schizophrenia and an early age at clinical onset. Arch Gen Psychiatry 54(12), 1104-1112.

Matsumoto, K., Kircher, T.T., Stokes, P.R., Brammer, M.J., Liddle, P.F., McGuire, P.K., 2013. Frequency and neural correlates of pauses in patients with formal thought disorder. Front Psychiatry 4 , 127.

McGuire, P.K., Quested, D.J., Spence, S.A., Murray, R.M., Frith, C.D., Liddle, P.F., 1998. Pathophysiology of 'positive' thought disorder in schizophrenia. Br J Psychiatry 173, 231-235.

Meisenzahl, E., Frodl, T., Muller, D., Schmitt, G., Gallinat, J., Zetzsche, T., Marcuse, A., Juckel, G., Leinsinger, G., Hahn, K., Moller, H., Hegerl, U., 2004. Superior temporal gyrus and P300 in schizophrenia: A combined ERP/structural magnetic resonance imaging investigation. J Psychiat Res 38(2), 153-162.

Menon, R.R., Barta, P.E., Aylward, E.H., Richards, S.S., Vaughn, D.D., Tien, A.Y., Harris, G.J., Pearlson, G.D., 1995. Posterior superior temporal gyrus in schizophrenia: grey matter changes and clinical correlates. Schizophr Res 16(2), 127-135.

Moher, D., Shamseer, L., Clarke, M., Ghersi, D., Liberati, A., Petticrew, M., Shekelle, P., Stewart, L.A., Group, P.-P., 2015. Preferred reporting items for systematic review and meta-analysis protocols (PRISMA-P) 2015 statement. Syst Rev 4, 1.

Morgan, C.J., Coleman, M.J., Ulgen, A., Boling, L., Cole, J.O., Johnson, F.V., Lerbinger, J., Bodkin, J.A., Holzman, P.S., Levy, D.L., 2017. Thought Disorder in Schizophrenia and Bipolar Disorder Probands, Their Relatives, and Nonpsychiatric Controls. Schizophr Bull 43(3), 523-535.

Murray, H.A., 1943. Thematic Apperception Test Manual. Harvard College, Boston, M. A.

Nagels, A., Fahrmann, P., Stratmann, M., Ghazi, S., Schales, C., Frauenheim, M., Turner, L., Hornig, T., Katzev, M., Muller-Isberner, R., Grosvald, M., Krug, A., Kircher, T., 2016. Distinct Neuropsychological Correlates in Positive and Negative Formal Thought Disorder Syndromes: The 
Thought and Language Disorder Scale in Endogenous Psychoses. Neuropsychobiology 73(3), 139147.

Nagels, A., Kircher, T., 2016. Symptoms and neurobiological models of language in schizophrenia., in: Hickok, G., Small, S.L. (Eds.), Neurobiology of language. Elsevier Ltd., Oxford, pp. 887-897.

Nakamura, M., Nestor, P.G., Levitt, J.J., Cohen, A.S., Kawashima, T., Shenton, M.E., McCarley, R.W., 2008. Orbitofrontal volume deficit in schizophrenia and thought disorder. Brain 131(Pt 1), 180-195.

Nestor, P.G., Shenton, M.E., Wible, C., Hokama, H., O'Donnell, B.F., Law, S., McCarley, R.W., 1998. A neuropsychological analysis of schizophrenic thought disorder. Schizophr Res 29(3), 217-225.

Niznikiewicz, M., Donnino, R., McCarley, R.W., Nestor, P.G., losifescu, D.V., O'Donnell, B., Levitt, J., Shenton, M.E., 2000. Abnormal angular gyrus asymmetry in schizophrenia. Am J Psychiatry 157(3), 428-437.

Palaniyappan, L., Mahmood, J., Balain, V., Mougin, O., Gowland, P.A., Liddle, P.F., 2015. Structural correlates of formal thought disorder in schizophrenia: An ultra-high field multivariate morphometry study. Schizophr Res 168(1-2), 305-312.

Petty, R.G., Barta, P.E., Pearlson, G.D., McGilchrist, I.K., Lewis, R.W., Tien, A.Y., Pulver, A., Vaughn, D., Casanova, M.F., Powers, R.E., 1995a. Reversal of asymmetry of the planum temporale in schizophrenia. Am J Psychiatry 152(5), 715-721.

Petty, R.G., Barta, P.E., Pearlson, G.D., McGilchrist, I.K., Lewis, R.W., Tien, A.Y., Pulver, A., Vaughn, D.D., Casanova, M.F., Powers, R.E., 1995b. Reversal of asymmetry of the planum temporale in schizophrenia. Am J Psychiatry 152(5), 715-721.

Pomarol-Clotet, E., Oh, T.M., Laws, K.R., McKenna, P.J., 2008. Semantic priming in schizophrenia: systematic review and meta-analysis. Br J Psychiatry 192(2), 92-97.

Portas, C.M., Goldstein, J.M., Shenton, M.E., Hokama, H.H., Wible, C.G., Fischer, I., Kikinis, R., Donnino, R., Jolesz, F.A., McCarley, R.W., 1998. Volumetric evaluation of the thalamus in schizophrenic male patients using magnetic resonance imaging. Biol Psychiatry 43(9), 649-659.

Price, C.J., 2010. The anatomy of language: a review of $100 \mathrm{fMRI}$ studies published in 2009. Ann N Y Acad Sci 1191, 62-88.

Radanovic, M., Sousa, R.T., Valiengo, L., Gattaz, W.F., Forlenza, O.V., 2013. Formal Thought Disorder and language impairment in schizophrenia. Arq Neuropsiquiatr 71(1), 55-60.

Ragland, J.D., Moelter, S.T., Bhati, M.T., Valdez, J.N., Kohler, C.G., Siegel, S.J., Gur, R.C., Gur, R.E., 2008. Effect of retrieval effort and switching demand on fMRI activation during semantic word generation in schizophrenia. Schizophr Res 99(1-3), 312-323.

Rajarethinam, R., DeQuardo, J., Nalepa, R., Tandon, R., 2000. Superior temporal gyrus in schizophrenia: A volumetric magnetic resonance imaging study. Schizophr Res 41(2), 303-312.

Rajarethinam, R., DeQuardo, J.R., Miedler, J., Arndt, S., Kirbat, R., Brunberg, J.A., Tandon, R., 2001. Hippocampus and amygdala in schizophrenia: assessment of the relationship of neuroanatomy to psychopathology. Psychiatry Res 108(2), 79-87.

Rapp, A.M., Langohr, K., Mutschler, D.E., Klingberg, S., Wild, B., Erb, M., 2013. Isn't it ironic? Neural correlates of irony comprehension in schizophrenia. PLoS One 8(9), e74224.

Rapp, A.M., Steinhauser, A.E., 2013. Functional MRI of sentence-level language comprehension in schizophrenia: A coordinate-based analysis. Schizophr Res 150(1), 107-113.

Roche, E., Creed, L., MacMahon, D., Brennan, D., Clarke, M., 2015. The Epidemiology and Associated Phenomenology of Formal Thought Disorder: A Systematic Review. Schizophr Bull 41(4), 951-962. 
Rossi, A., Serio, A., Stratta, P., Petruzzi, C., Schiazza, G., Mancini, F., Casacchia, M., 1994. Planum temporale asymmetry and thought disorder in schizophrenia. Schizophr Res 12(1), 1-7.

Rossler, W., Hengartner, M.P., Ajdacic-Gross, V., Haker, H., Angst, J., 2013. Lifetime and 12-month prevalence rates of sub-clinical psychosis symptoms in a community cohort of 50-year-old individuals. Eur Psychiatry 28(5), 302-307.

Sabri, O., Erkwoh, R., Schreckenberger, M., Owega, A., Sass, H., Buell, U., 1997. Correlation of positive symptoms exclusively to hyperperfusion or hypoperfusion of cerebral cortex in never-treated schizophrenics. Lancet 349(9067), 1735-1739.

Sallet, P.C., Elkis, H., Alves, T.M., Oliveira, J.R., Sassi, E., de Castro, C.C., Busatto, G.F., Gattaz, W.F., 2003. Rightward cerebral asymmetry in subtypes of schizophrenia according to Leonhard's classification and to DSM-IV: a structural MRI study. Psychiatry Res 123(1), 65-79.

Sans-Sansa, B., McKenna, P.J., Canales-Rodriguez, E.J., Ortiz-Gil, J., Lopez-Araquistain, L., Sarro, S., Duenas, R.M., Blanch, J., Salvador, R., Pomarol-Clotet, E., 2013. Association of formal thought disorder in schizophrenia with structural brain abnormalities in language-related cortical regions. Schizophr Res 146(1-3), 308-313.

Shapleske, J., Rossell, S.L., Simmons, A., David, A.S., Woodruff, P.W., 2001. Are auditory hallucinations the consequence of abnormal cerebral lateralization? A morphometric MRI study of the sylvian fissure and planum temporale. Biol Psychiatry 49(8), 685-693.

Shenton, M.E., Kikinis, R., Jolesz, F.A., Pollak, S.D., LeMay, M., Wible, C.G., Hokama, H., Martin, J., Metcalf, D., Coleman, M., et al., 1992. Abnormalities of the left temporal lobe and thought disorder in schizophrenia. A quantitative magnetic resonance imaging study. N Engl J Med 327(9), 604-612.

Shenton, M.E., Kikinis, R., McCarley, R.W., Metcalf, D., Tieman, J., Jolesz, F.A., 1991. Application of automated MRI volumetric measurement techniques to the ventricular system in schizophrenics and normal controls. Schizophr Res 5(2), 103-113.

Sigaudo, M., Crivelli, B., Castagna, F., Giugiario, M., Mingrone, C., Montemagni, C., Rocca, G., Rocca, P., 2014. Quality of life in stable schizophrenia: the relative contributions of disorganization and cognitive dysfunction. Schizophr Res 153(1-3), 196-203.

Skudlarski, P., Jagannathan, K., Anderson, K., Stevens, M.C., Calhoun, V.D., Skudlarska, B.A., Pearlson, G., 2010. Brain connectivity is not only lower but different in schizophrenia: A combined anatomical and functional approach. Biol Psychiat 68(1), 61-69.

Stegmayer, K., Strik, W., Federspiel, A., Wiest, R., Bohlhalter, S., Walther, S., 2017. Specific cerebral perfusion patterns in three schizophrenia symptom dimensions. Schizophr Res 190, 96-101.

Strik, W., Dierks, T., Hubl, D., Horn, H., 2008. Hallucinations, thought disorders, and the language domain in schizophrenia. Clin EEG Neurosci 39(2), 91-94.

Strik, W., Wopfner, A., Horn, H., Koschorke, P., Razavi, N., Walther, S., Wirtz, G., 2010. The Bern psychopathology scale for the assessment of system-specific psychotic symptoms. Neuropsychobiology 61(4), 197-209.

Subotnik, K.L., Bartzokis, G., Green, M.F., Nuechterlein, K.H., 2003. Neuroanatomical correlates of formal thought disorder in schizophrenia. Cog Neuropsychiatry 8(2), 81-88.

Sumner, P.J., Bell, I.H., Rossell, S.L., 2017. A systematic review of the structural neuroimaging correlates of thought disorder. Neurosci Biobehav Rev 84, 299-315.

Sun, J., Maller, J.J., Guo, L., Fitzgerald, P.B., 2009. Superior temporal gyrus volume change in schizophrenia: a review on region of interest volumetric studies. Brain Res Rev 61(1), 14-32.

Tagamets, M.A., Cortes, C.R., Griego, J.A., Elvevag, B., 2014. Neural correlates of the relationship between discourse coherence and sensory monitoring in schizophrenia. Cortex 55, 77-87. 
Takahashi, T., Zhou, S.Y., Nakamura, K., Tanino, R., Furuichi, A., Kido, M., Kawasaki, Y., Noguchi, K., Seto, H., Kurachi, M., Suzuki, M., 2011. Longitudinal volume changes of the pituitary gland in patients with schizotypal disorder and first-episode schizophrenia. Prog Neuropsychopharmacol Biol Psychiatry 35(1), 177-183.

Tan, E.J., Rossell, S.L., 2017. Formal thought disorder and neurocognition in schizophrenia: The question of individual mechanisms. Schizophr Res 190, 189-190.

Tan, E.J., Thomas, N., Rossell, S.L., 2014. Speech disturbances and quality of life in schizophrenia: differential impacts on functioning and life satisfaction. Compr Psychiatry 55(3), 693-698.

Tirupati, N.S., Rangaswamy, T., Raman, P., 2004. Duration of untreated psychosis and treatment outcome in schizophrenia patients untreated for many years. Aust N Z J Psychiatry 38(5), 339-343.

van Veelen, N.M., Vink, M., Ramsey, N.F., Sommer, I.E., van Buuren, M., Hoogendam, J.M., Kahn, R.S., 2011. Reduced language lateralization in first-episode medication-naive schizophrenia. Schizophr Res 127(1-3), 195-201.

Viher, P.V., Stegmayer, K., Giezendanner, S., Federspiel, A., Bohlhalter, S., Vanbellingen, T., Wiest, R., Strik, W., Walther, S., 2016a. Cerebral white matter structure is associated with DSM-5 schizophrenia symptom dimensions. Neuroimage Clin 12, 93-99.

Viher, P.V., Stegmayer, K., Giezendanner, S., Federspiel, A., Bohlhalter, S., Wiest, R., Strik, W., Walther, S., 2016b. White matter correlates of the disorganized speech dimension in schizophrenia. Eur Arch Psychiatry Clin Neurosci, doi: 10.1007/s00406-016-0753-y.

Vita, A., Dieci, M., Giobbio, G.M., Caputo, A., Ghiringhelli, L., Comazzi, M., Garbarini, M., Mendini, A.P., Morganti, C., Tenconi, F., et al., 1995. Language and thought disorder in schizophrenia: brain morphological correlates. Schizophr Res 15(3), 243-251.

Weinstein, S., Werker, J.F., Vouloumanos, A., Woodward, T.S., Ngan, E.T., 2006. Do you hear what I hear? Neural correlates of thought disorder during listening to speech in schizophrenia. Schizophr Res 86(1-3), 130-137.

Weinstein, S., Woodward, T.S., Ngan, E.T., 2007. Brain activation mediates the association between structural abnormality and symptom severity in schizophrenia. Neuroimage 36(1), 188-193.

Wensing, T., Cieslik, E.C., Muller, V.I., Hoffstaedter, F., Eickhoff, S.B., Nickl-Jockschat, T., 2017. Neural correlates of formal thought disorder: An activation likelihood estimation meta-analysis. Hum Brain Mapp 38(10), 4946-4965.

Willits, J.A., Rubin, T., Jones, M.N., Minor, K.S., Lysaker, P.H., 2017. Evidence of disturbances of deep levels of semantic cohesion within personal narratives in schizophrenia. Schizophr Res, doi: 10.1016/j.schres.2017.11.014.

Yalincetin, B., Bora, E., Binbay, T., Ulas, H., Akdede, B.B., Alptekin, K., 2016a. Formal thought disorder in schizophrenia and bipolar disorder: A systematic review and meta-analysis. Schizophr Res 185: 2-8.

Yalincetin, B., Ulas, H., Var, L., Binbay, T., Akdede, B.B., Alptekin, K., 2016b. Relation of formal thought disorder to symptomatic remission and social functioning in schizophrenia. Compr Psychiatry 70, 98-104.

Yamasue, H., Iwanami, A., Hirayasu, Y., Yamada, H., Abe, O., Kuroki, N., Fukuda, R., Tsujii, K., Aoki, S., Ohtomo, K., Kato, N., Kasai, K., 2004. Localized volume reduction in prefrontal, temporolimbic, and paralimbic regions in schizophrenia: an MRI parcellation study. Psychiatry Res 131(3), 195-207.

Yarkoni, T., 2009. Big Correlations in Little Studies: Inflated fMRI Correlations Reflect Low Statistical Power-Commentary on Vul et al. (2009). Perspect Psychol Sci 4(3), 294-298. 


\section{TABLES AND FIGURES}

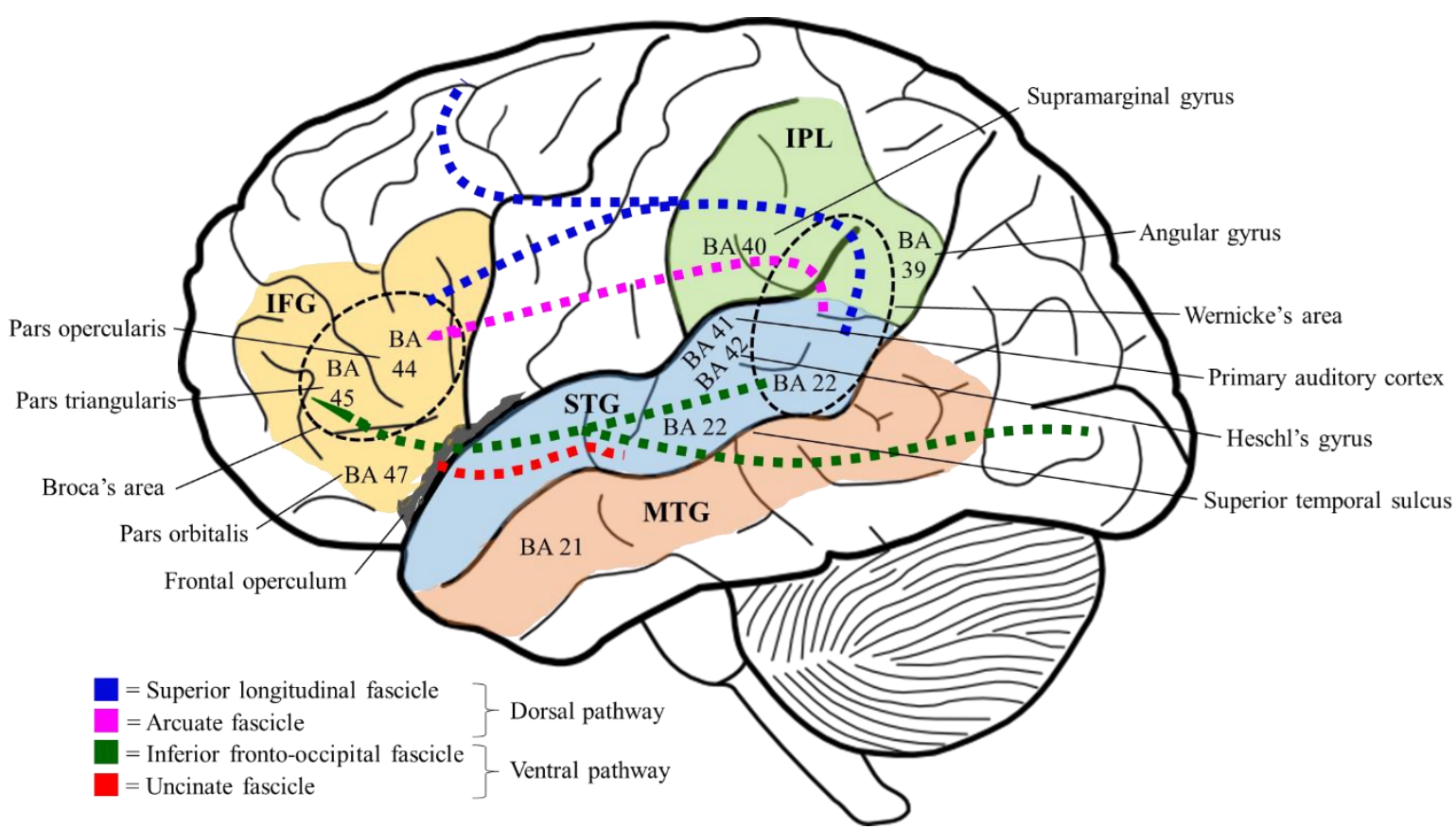

Figure 1. Schematic illustration of the major cortical regions and white matter tracts of the language network in the left hemisphere ((adapted from Friederici, 2011, 2012; Friederici and Gierhan, 2013; Price, 2010)).

Notes. $\mathrm{BA}=$ Brodmann Area, IFG $=$ inferior frontal gyrus, $\mathrm{IPL}=$ inferior parietal lobe, $\mathrm{MTG}=$ middle temporal gyrus, $\mathrm{STG}=$ superior temporal gyrus . 


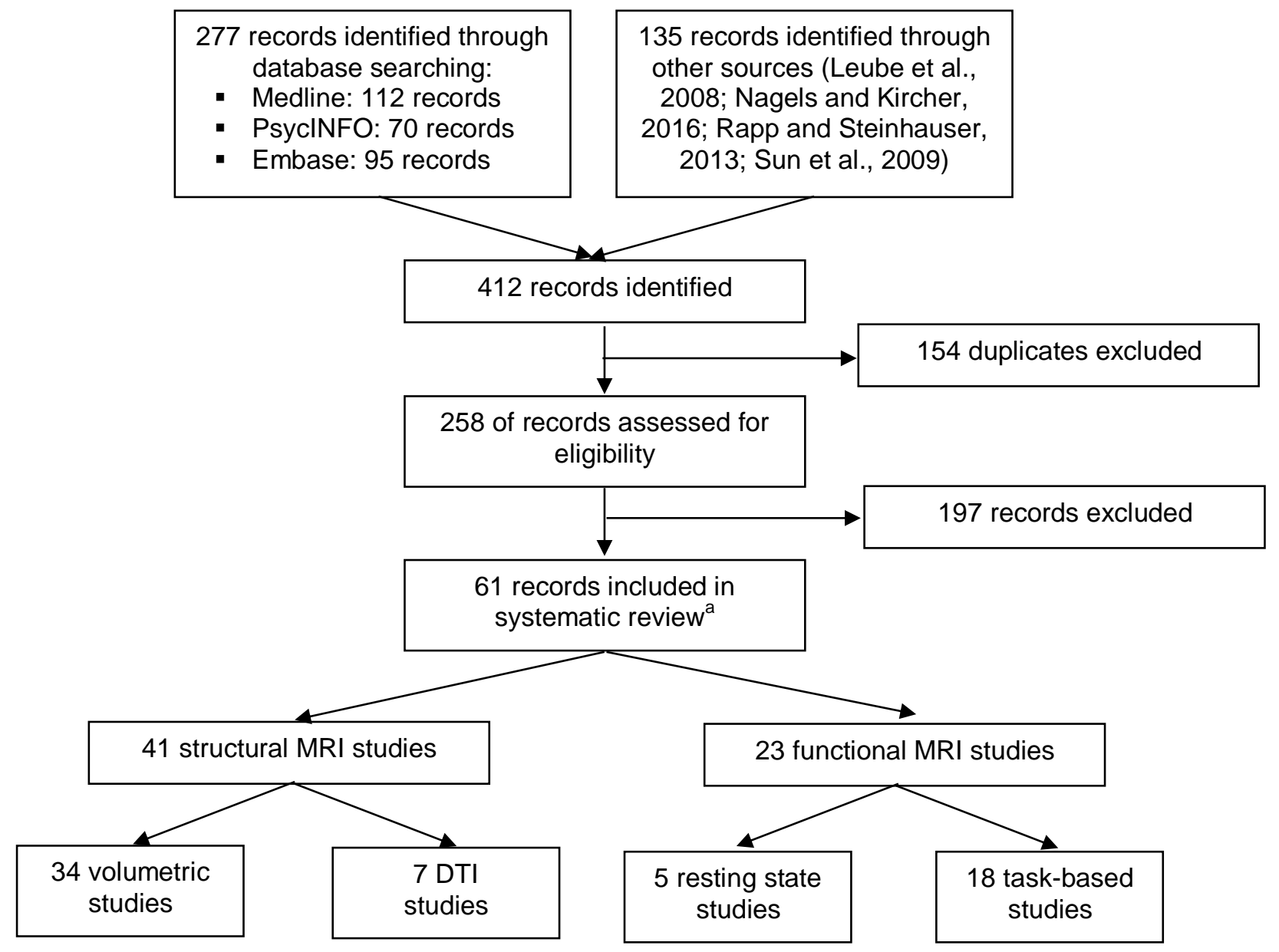

Figure 2. Flow chart of the selection process.

Notes. DTI = Diffusion Tensor Imaging, MRI = magnetic resonance imaging

${ }^{a}$ Three studies reported both structural and functional results. They are listed twice; once under structural MRI studies and once under functional MRI studies. 

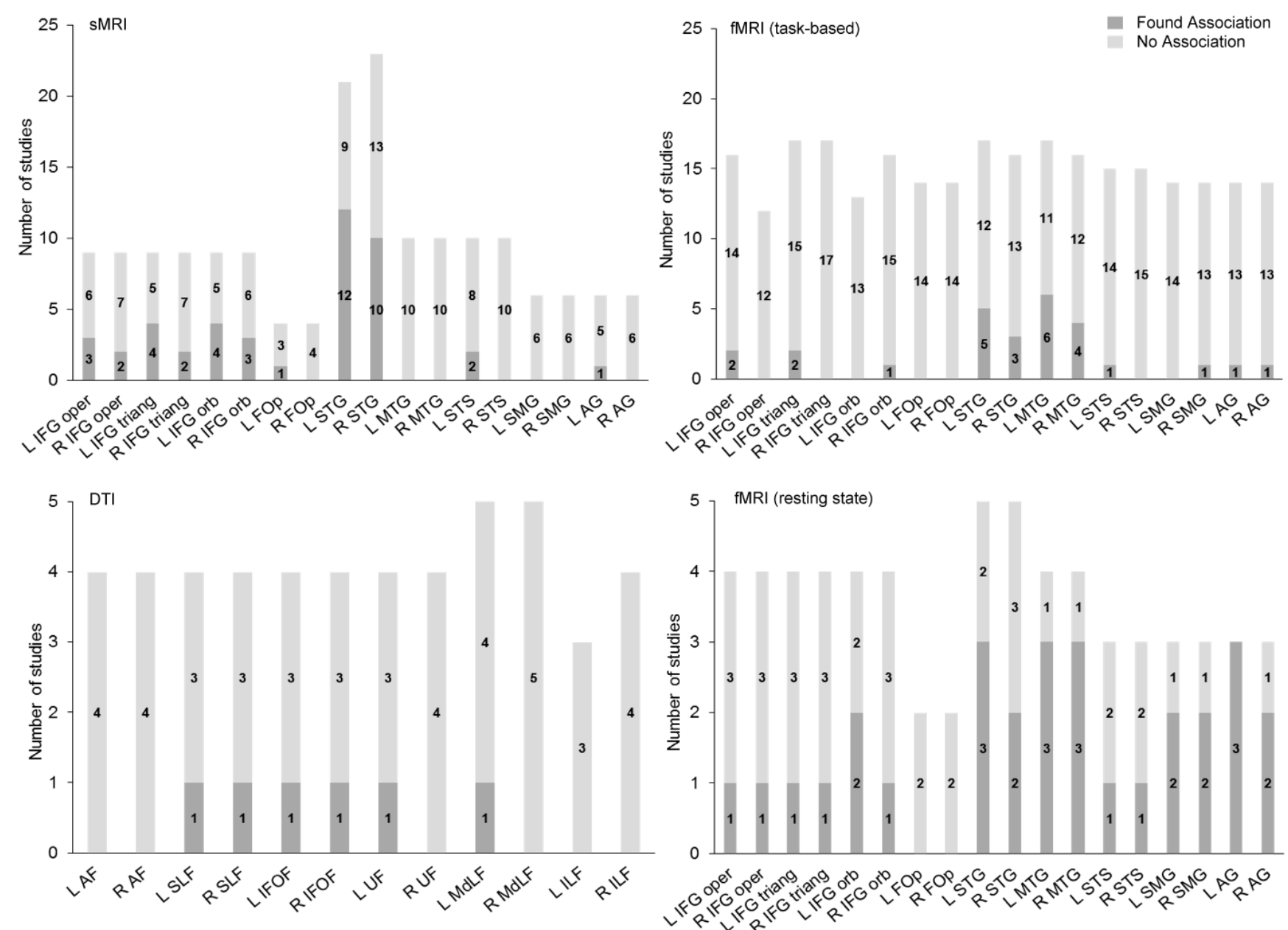

Figure 3. Top left: sMRI studies, bottom left: DTI studies, top right: task-based fMRI studies, bottom right: resting state fMRI studies. Dark grey: Number of studies that found an association between FTD and the language network. Light grey: Number of studies that did not find an association between FTD and the language network.

Notes. $\mathrm{AF}=$ arcuate fascicle, $\mathrm{AG}=$ angular gyrus, IFG oper $=$ inferior frontal gyrus pars opercularis, IFG orb $=$ inferior frontal gyrus pars orbitalis, IFG triang $=$ inferior frontal gyrus pars triangularis, ILF = inferior longitudinal fascicle, IFOF = inferior fronto-occipital fascicle, FOp = frontal operculum, MdLF = middle 
longitudinal fascicle, MTG = middle temporal gyrus, SLF = superior longitudinal fascicle, SMG = supramarginal gyrus, STG = superior temporal gyrus, STS = superior temporal sulcus, UF $=$ uncinate fascicle. 


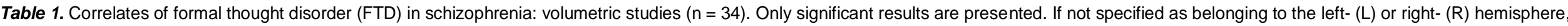
the results were found bilaterally. If the study design included three groups (HC, SZ-FTD, SZ-nFTD), only the comparison between SZ-FTD and SZ-FTD is presented.

\begin{tabular}{|c|c|c|c|c|c|c|c|c|}
\hline Authors & Patients/HC (n) & Age (M/SD) & FTD assessment & Imaging scope & Increased volume & Reduced volume & Positive correlation & Negative correlation \\
\hline $\begin{array}{l}\text { Anderson et } \\
\text { al. (2002) }\end{array}$ & $\begin{array}{l}\text { SZ: } 16 \\
\text { HC: } 15\end{array}$ & $\begin{array}{l}42.50(8.79) \\
41.67(7.51)\end{array}$ & TDI & ROI: STG, AHi, PHG & & & PHG & $\begin{array}{l}\text { L STG, R posterior } \\
\text { STG }\end{array}$ \\
\hline $\begin{array}{l}\text { Barta et al. } \\
\text { (1997) }\end{array}$ & $\begin{array}{l}\text { SZ: } 28 \\
H C: 32\end{array}$ & $\begin{array}{l}41.57(12.93) \\
44.34(19.39)\end{array}$ & $\begin{array}{l}\text { SAPS positive FTD } \\
\text { subscale }\end{array}$ & ROI: PT & & & & PT \\
\hline $\begin{array}{l}\text { DeLisi et al. } \\
\text { (1994) }\end{array}$ & $\begin{array}{l}\text { SZ: } 85 \\
\text { HC: } 40\end{array}$ & $\begin{array}{l}26.94(7.25) \\
27.1(7.26)\end{array}$ & SADS FTD & ROI: PT, STG & & & & \\
\hline $\begin{array}{l}\text { DeLisi and } \\
\text { Hoff (2005) }\end{array}$ & $\begin{array}{l}\text { SZ: } 27 \\
\text { HC: } 10\end{array}$ & & $\begin{array}{l}\text { BPRS conceptual } \\
\text { disorganization at 10- } \\
\text { year follow-up }\end{array}$ & ROI: STG, TL & & & & \\
\hline $\begin{array}{l}\text { Dieci et al. } \\
(1998)\end{array}$ & SZ: 19 & $25.6(6.3)$ & TLC & $\begin{array}{l}\text { ROI: PFL, TL, STG, } \\
\text { lateral ventricular } \\
\text { segments }\end{array}$ & & & & $\begin{array}{l}\text { L PFL/STG ratio } \\
\text { (relatively smaller PFL } \\
\text { and larger STG) }\end{array}$ \\
\hline $\begin{array}{l}\text { Elfaki et al. } \\
\text { (2016) }\end{array}$ & $\begin{array}{l}\text { SZ: } 54 \\
H C: 82\end{array}$ & $\begin{array}{l}31.39(6.4) \\
29.28(6.03)\end{array}$ & $\begin{array}{l}\text { PANSS conceptual } \\
\text { disorganization item }\end{array}$ & ROI: amg, $\mathrm{Hi}$ & & & & $\mathrm{R} \mathrm{Hi}, \mathrm{amg}$ \\
\hline $\begin{array}{l}\text { Fukuzako et } \\
\text { al. (1996) }\end{array}$ & $\begin{array}{l}\text { SZ: } 18 \\
\text { HC: } 18\end{array}$ & $\begin{array}{l}37.8(5.3) \\
38.1(5.9)\end{array}$ & $\begin{array}{l}\text { SAPS positive FTD } \\
\text { subscale }\end{array}$ & $\mathrm{ROI}: \mathrm{Hi}$ & & & & Hi length \\
\hline $\begin{array}{l}\text { Holinger et } \\
\text { al. (1999) }\end{array}$ & $\begin{array}{l}\text { SZ: } 8 \\
\text { HC: } 10\end{array}$ & $\begin{array}{l}38(9) \\
31(8)\end{array}$ & $\begin{array}{l}\text { Harrow and Quinlan's } \\
\text { (1985) scale }\end{array}$ & ROI: STG & & & $\mathrm{R}$ anterior STG & \\
\hline $\begin{array}{l}\text { Horn et al. } \\
\text { (2009) }\end{array}$ & $\begin{array}{l}\text { SZ: } 13 \\
\text { HC: } 13\end{array}$ & $\begin{array}{l}29.6(11.2) \\
26.6(4.6)\end{array}$ & TLC & Whole-brain & & & & $\begin{array}{l}\text { L sts, anterior cg, L } \\
\text { ANG, PCun, L } \\
\text { posterior STG }\end{array}$ \\
\hline $\begin{array}{l}\text { Horn et al. } \\
(2010)\end{array}$ & $\begin{array}{l}\text { SZ: } 20 \\
\text { HC: } 20\end{array}$ & $\begin{array}{l}30.1(10.0) \\
30.1(10.0)\end{array}$ & TLC & Whole-brain & & & & $\begin{array}{l}\text { R Cun/LgG, R MOrG, } \\
\text { L TmP, L sts }\end{array}$ \\
\hline $\begin{array}{l}\text { Kuhn et al. } \\
\text { (2012) }\end{array}$ & $\begin{array}{l}\text { SZ: } 29 \\
\text { HC: } 45\end{array}$ & $\begin{array}{l}27.6(6.8) \\
31.3(7.7)\end{array}$ & BPRS item 4 & $\mathrm{ROI}: \mathrm{Cb}$ & & & & L Cruss I/II \\
\hline $\begin{array}{l}\text { Levitt et al. } \\
\text { (1999) }\end{array}$ & $\begin{array}{l}\text { SZ: } 15 \\
\text { HC: } 15\end{array}$ & $\begin{array}{l}37.6(9.3) \\
37.9(9.8)\end{array}$ & $\begin{array}{l}\text { SAPS positive FTD } \\
\text { subscale }\end{array}$ & ROI: Cb, Ver & & & Ver & \\
\hline $\begin{array}{l}\text { Marsh et al. } \\
\text { (1997) }\end{array}$ & $\begin{array}{l}\text { SZ: } 56 \\
\text { HC: } 52\end{array}$ & $\begin{array}{l}35.9(8.3) \\
37(8.9)\end{array}$ & $\begin{array}{l}\text { BPRS conceptual } \\
\text { disorganization }\end{array}$ & $\begin{array}{l}\text { ROI: TL, STG, Hi, } \\
\text { TLV, LV, 3V, } \\
\text { frontoparietal volumes }\end{array}$ & & & & STG \\
\hline $\begin{array}{l}\text { Meisenzahl } \\
\text { et al. (2004) }\end{array}$ & $\begin{array}{l}\text { SZ: } 50 \\
H C: 50\end{array}$ & $\begin{array}{l}30(8.4) \\
30.2(8.8)\end{array}$ & $\begin{array}{l}\text { BPRS thought } \\
\text { disorder index }\end{array}$ & ROI: STG & & & & \\
\hline
\end{tabular}


Table 1. Continuing

\begin{tabular}{|c|c|c|c|c|c|c|c|c|}
\hline Authors & Patients/HC (n) & Age (M/SD) & FTD assessment & Imaging scope & Increased volume & Reduced volume & Positive correlation & Negative correlation \\
\hline $\begin{array}{l}\text { Menon et al. } \\
\text { (1995) }\end{array}$ & $\begin{array}{l}\text { SZ: } 20 \\
H C: 20\end{array}$ & $\begin{array}{l}29.7(5.6) \\
29.8(6.2)\end{array}$ & $\begin{array}{l}\text { SAPS positive FTD } \\
\text { subscale }\end{array}$ & $\begin{array}{l}\text { ROI: middle and } \\
\text { posterior STG }\end{array}$ & & & & \\
\hline $\begin{array}{l}\text { Nakamura et } \\
\text { al. (2008) }\end{array}$ & $\begin{array}{l}\text { SZ: } 24 \\
\text { HC: } 25\end{array}$ & $39.1(10.3)$ & $\begin{array}{l}\text { SAPS positive FTD } \\
\text { subscale }\end{array}$ & $\begin{array}{l}\text { ROI: REC, MOrG, } \\
\text { LOrG }\end{array}$ & & & & L MOrG \\
\hline $\begin{array}{l}\text { Nestor et al. } \\
\text { (1998) }\end{array}$ & SZ: 15 & 37.6 & TDI & $\begin{array}{l}\text { ROI: prefrontal cortex, } \\
\mathrm{Pu}, \mathrm{Cd}, \mathrm{GP}\end{array}$ & & & & \\
\hline $\begin{array}{l}\text { Niznikiewicz } \\
\text { et al. (2000) }\end{array}$ & $\begin{array}{l}\text { SZ: } 15 \\
\text { HC: } 15\end{array}$ & $20-55$ & TDI & $\begin{array}{l}\text { ROI: PL, IPL, ANG, } \\
\text { SMG, SPG, PoG }\end{array}$ & & & & \\
\hline $\begin{array}{l}\text { Palaniyappan } \\
\text { et al. (2015) }\end{array}$ & $\begin{array}{l}\text { SZ: } 19 \\
\text { HC: } 20\end{array}$ & $\begin{array}{l}33.2(9.8) \\
32(8.2)\end{array}$ & $\begin{array}{l}\text { TLI 'impoverished } \\
\text { thinking' and } \\
\text { 'disorganised thinking' } \\
\text { subscales }\end{array}$ & Whole-brain & & & $\begin{array}{l}\text { 'impoverished } \\
\text { thinking': dorsal } \\
\text { anterior cg, superior, } \\
\text { inferior, middle, and } \\
\text { medial FL }\end{array}$ & $\begin{array}{l}\text { 'impoverished } \\
\text { thinking': VStr, Ins, } \\
\text { STG, posterior cg, } \\
\text { Pcun }\end{array}$ \\
\hline $\begin{array}{l}\text { Petty et al. } \\
\text { (1995a) }\end{array}$ & $\begin{array}{l}\text { SZ: } 14 \\
\text { HC: } 14\end{array}$ & $\begin{array}{l}36.6(17.2) \\
36 .(15.5)\end{array}$ & $\begin{array}{l}\text { SAPS positive FTD } \\
\text { subscale }\end{array}$ & ROI: PT & & & PT asymmetry $(R>L)$ & \\
\hline $\begin{array}{l}\text { Portas et al. } \\
\text { (1998) }\end{array}$ & $\begin{array}{l}\text { SZ: } 15 \\
\text { HC: } 15\end{array}$ & $37.6(9.3)$ & TDI & ROI: Th & & & & \\
\hline $\begin{array}{l}\text { Rajarethinam } \\
\text { et al. (2000) }\end{array}$ & $\begin{array}{l}\text { SZ: } 20 \\
\text { HC: } 20\end{array}$ & $\begin{array}{l}33.5(12.7) \\
33.9(12.6)\end{array}$ & $\begin{array}{l}\text { BPRS conceptual } \\
\text { disorganization }\end{array}$ & ROI: STG & & & & LSTG \\
\hline $\begin{array}{l}\text { Rajarethinam } \\
\text { et al. (2001) }\end{array}$ & $\begin{array}{l}\text { SZ: } 20 \\
\text { HC: } 20\end{array}$ & $\begin{array}{l}33.5(12.7) \\
33.9(12.6)\end{array}$ & $\begin{array}{l}\text { BPRS conceptual } \\
\text { disorganization }\end{array}$ & $\begin{array}{l}\text { ROI: Amg, anterior } \\
\text { and posterior halves of } \\
\mathrm{Hi}, \mathrm{Hi}, \mathrm{AHi}\end{array}$ & & & & L Amg, L AHi \\
\hline $\begin{array}{l}\text { Rossi et al. } \\
\text { (1994) }\end{array}$ & $\begin{array}{l}\text { SZ-FTD: } 10 \\
\text { SZ-nFTD: } 12 \\
\text { HC: } 23\end{array}$ & $\begin{array}{l}28.6(5.68) \\
31.66(3.28) \\
31.52(4.54)\end{array}$ & $\begin{array}{l}\text { K-MS 'incoherence } \\
\text { and irrelevance of } \\
\text { speech' item }\end{array}$ & ROI: PT & & $\begin{array}{l}\text { SZ-FTD < SZ-nFTD: } \\
\text { laterality index PT } \\
\text { (less L>R PT } \\
\text { asymmetry) }\end{array}$ & $\begin{array}{l}\text { Laterality index PT } \\
\text { (less } \mathrm{L}>\mathrm{R} \mathrm{PT} \\
\text { asymmetry) }\end{array}$ & \\
\hline $\begin{array}{l}\text { Sallet et al. } \\
\text { (2003) }\end{array}$ & $\begin{array}{l}\text { SZ: } 40 \\
\text { HC: } 20\end{array}$ & $\begin{array}{l}34(8) \\
31.5(10.8)\end{array}$ & $\begin{array}{l}\text { PANSS conceptual } \\
\text { disorganization item }\end{array}$ & $\begin{array}{l}\mathrm{ROI} \text { : hemisphere, } \mathrm{Hi} \text {, } \\
\mathrm{PT} \text {, ventricular-brain } \\
\text { ratio }\end{array}$ & & & & \\
\hline $\begin{array}{l}\text { Sans-Sansa } \\
\text { et al. (2013) }\end{array}$ & $\begin{array}{l}\text { SZ-FTD: } 20 \\
\text { SZ-nFTD: } 31 \\
\text { HC: } 59\end{array}$ & $\begin{array}{l}46.10(8.5) \\
40.71(8.61) \\
38.31(10.49)\end{array}$ & $\begin{array}{l}\text { TLC global score, } \\
\text { fluent 'disorganization' } \\
\text { subscale, 'poverty of } \\
\text { content of speech' } \\
\text { item }\end{array}$ & Whole-brain & & $\begin{array}{l}\text { SZ-FTD < SZ-nFTD: } \\
\text { OFC, ventromedial } \\
\text { PFL, L inferior Fop } \\
\text { and pars triangularis, } \\
\text { L STG }\end{array}$ & & $\begin{array}{l}\text { 'disorganization': L } \\
\text { STG, L inferior Fop } \\
\text { 'poverty of content of } \\
\text { speech': ventromedial } \\
\text { PFL, OFC }\end{array}$ \\
\hline $\begin{array}{l}\text { Shapleske et } \\
\text { al. (2001) }\end{array}$ & $\begin{array}{l}\text { SZ: } 74 \text { (44 with } \\
\text { AH, } 30 \text { no AH) } \\
\text { HC: } 32\end{array}$ & $\begin{array}{l}34.1(8.5) \\
33.5(8.5)\end{array}$ & $\begin{array}{l}\text { SAPS positive FTD } \\
\text { subscale }\end{array}$ & ROI: SF, PT & & & & $\begin{array}{l}\text { SZ-AH: horizontal SF } \\
\text { laterality coefficient } \\
\text { (grater leftwards } \\
\text { asymmetry) }\end{array}$ \\
\hline
\end{tabular}


Table 1. Continuing

\begin{tabular}{|c|c|c|c|c|c|c|c|c|}
\hline Authors & Patients/HC (n) & Age (M/SD) & FTD assessment & Imaging scope & Increased volume & Reduced volume & Positive correlation & Negative correlation \\
\hline $\begin{array}{l}\text { Shenton et } \\
\text { al. (1991) }\end{array}$ & $\begin{array}{l}\text { SZ: } 10 \\
\text { HC: } 12\end{array}$ & $\begin{array}{l}40.9(6.15) \\
40(9.27)\end{array}$ & TDI & $\begin{array}{l}\text { ROI: ventricular } \\
\text { system }\end{array}$ & & & & $\begin{array}{l}\mathrm{L}>\mathrm{R} \text { ventricular } \\
\text { system asymmetry }\end{array}$ \\
\hline $\begin{array}{l}\text { Shenton et } \\
\text { al. (1992) }\end{array}$ & $\begin{array}{l}\text { SZ: } 15 \\
\text { HC: } 15\end{array}$ & $\begin{array}{l}37(9) \\
37(9)\end{array}$ & TDI & ROI: STG & & & & L posterior STG \\
\hline $\begin{array}{l}\text { Subotnik et } \\
\text { al. (2003) }\end{array}$ & SZ: 15 & $32.8(5.8)$ & $\mathrm{BIZ}$ & $\begin{array}{l}\text { ROI: STG, anterior } \mathrm{Hi} \text {, } \\
\text { Amg }\end{array}$ & & & & STG \\
\hline $\begin{array}{l}\text { Takahashi et } \\
\text { al. (2011) }\end{array}$ & $\begin{array}{l}\text { SZ: } 18 \\
\text { Schizotypal: } 13 \\
\text { HC: } 20\end{array}$ & $\begin{array}{l}23.1(4.7) \\
22.8(5.0) \\
23.2(5.7)\end{array}$ & $\begin{array}{l}\text { SAPS positive FTD } \\
\text { subscale at } 2.7 \text {-years } \\
\text { follow-up }\end{array}$ & ROI: pituitary gland & & & Pituitary gland & \\
\hline $\begin{array}{l}\text { Vita et al. } \\
\text { (1995) }\end{array}$ & $\begin{array}{l}\text { SZ: } 19 \\
\text { HC: } 15\end{array}$ & $\begin{array}{l}25.6(6.3) \\
28.6(8.2)\end{array}$ & $\begin{array}{l}\text { TLC total score and } \\
\text { single items }\end{array}$ & $\begin{array}{l}\text { ROI: PFL, TL, STG, } \\
\text { lateral ventricles }\end{array}$ & & & R STG & PFL \\
\hline $\begin{array}{l}\text { Weinstein et } \\
\text { al. (2007) }\end{array}$ & SZ: 12 & $35.9(12.6)$ & TLI & ROI: PT & & & & PT \\
\hline $\begin{array}{l}\text { Yamasue et } \\
\text { al. (2004) }\end{array}$ & $\begin{array}{l}\text { SZ: } 27 \\
\text { HC: } 27\end{array}$ & $\begin{array}{l}30.4(7.9) \\
30(5.6)\end{array}$ & $\begin{array}{l}\text { PANSS conceptual } \\
\text { disorganization item }\end{array}$ & $\begin{array}{l}\text { ROI: prefrontal cortex, } \\
\text { anterior cg, TL } \\
\text { subregions }\end{array}$ & & & & L Ins \\
\hline
\end{tabular}

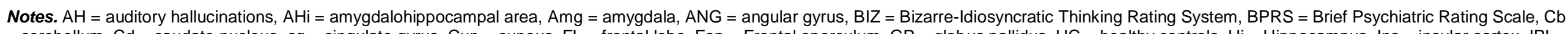

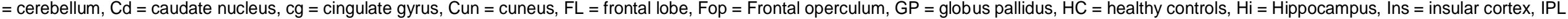

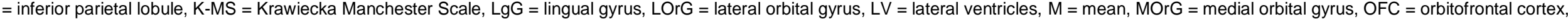
PANSS $=$ Positive And Negative Symptom Scale, $\mathrm{PCun}=$ precuneus, $\mathrm{PFL}=$ prefrontal lobe, $\mathrm{PHG}=$ parahippocampal gyrus, $\mathrm{PL}=\mathrm{parietal}$ lobe, $\mathrm{PoG}=$ postcentral gyrus, $\mathrm{PT}=$ planum temporale, $\mathrm{Pu}=$

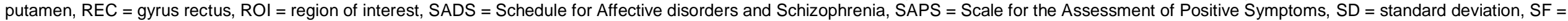

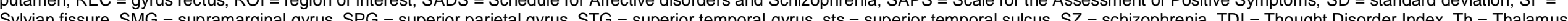

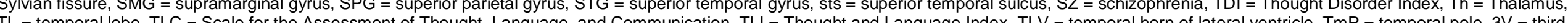

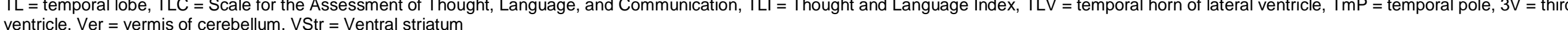




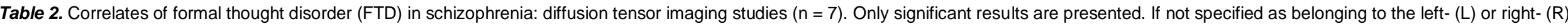
hemisphere, the results were found bilaterally.

\begin{tabular}{|c|c|c|c|c|c|c|c|c|}
\hline Authors & Patients/HC (n) & Age (M/SD) & FTD assessment & Imaging scope & Increased FA & Reduced FA & Positive correlation & Negative correlation \\
\hline $\begin{array}{l}\text { Arnedo et al. } \\
\text { (2015) }\end{array}$ & $\begin{array}{l}\text { SZ: } 47 \\
\text { HC: } 36\end{array}$ & $\begin{array}{l}34.2(8.5) \\
36.9(9.1)\end{array}$ & $\begin{array}{l}\text { SAPS positive FTD } \\
\text { subscale and items, } \\
\text { SANS alogia items }\end{array}$ & Whole-brain & & $\begin{array}{l}\text { Pressured speech, } \\
\text { distractible speech: } \\
\text { Genu of cc, fornix } \\
\text { Poverty of speech: } \\
\text { Splenium of cc, } \\
\text { posterior and } \\
\text { retrolenticular limb of } \\
\text { IC }\end{array}$ & & \\
\hline $\begin{array}{l}\text { Asami et al. } \\
\text { (2013) }\end{array}$ & $\begin{array}{l}\text { SZ: } 26 \\
\text { HC: } 25\end{array}$ & $\begin{array}{l}40.8(10.4) \\
40.4(10.0)\end{array}$ & $\begin{array}{l}\text { PANSS Disorganized } \\
\text { Thoughts Factor }\end{array}$ & ROI: MdLF & & & & L MdLF \\
\hline $\begin{array}{l}\text { Bopp et al. } \\
\text { (2016) }\end{array}$ & $\begin{array}{l}\text { SZ: } 26 \\
\text { HC: } 26\end{array}$ & $\begin{array}{l}34.46(10.71) \\
35.73(10.61)\end{array}$ & SAPS Disorganization & Whole-brain & & & & $\begin{array}{l}R \text { cingulum bundle of } \\
\mathrm{cg}\end{array}$ \\
\hline $\begin{array}{l}\text { Bijanki et al. } \\
\text { (2015) }\end{array}$ & $\begin{array}{l}\text { Chronic SZ: } 59 \\
\text { First-episode } \\
\text { SZ: } 31\end{array}$ & $\begin{array}{l}37.7(8.7) \\
23.1(4.4)\end{array}$ & $\begin{array}{l}\text { SANS poverty of } \\
\text { speech, poverty of } \\
\text { speech content }\end{array}$ & Whole-brain & & & cerebrum & \\
\hline $\begin{array}{l}\text { Skudlarski et } \\
\text { al. (2010) }\end{array}$ & $\begin{array}{l}\text { SZ: } 27 \\
\text { HC: } 27\end{array}$ & $\begin{array}{l}38(10) \\
39(11)\end{array}$ & TDI & Whole-brain & & & & Whole brain \\
\hline $\begin{array}{l}\text { Viher et al. } \\
\text { (2016b) }\end{array}$ & SZ: 61 & $37.3(11.3)$ & $\begin{array}{l}\text { BPS language } \\
\text { dimension }\end{array}$ & Whole-brain & & & & $\begin{array}{l}\text { Body/splenium of cc, } \\
\mathrm{R} \text { anterior limb of IC, } \mathrm{L} \\
\text { retrolenticular limb of } \\
\text { IC, anterior CR, L } \\
\text { superior CR, posterior } \\
\text { CR, anterior TR, L } \\
\text { posterior TR, L EC, } \\
\text { SLF, L CST, FMi, } \\
\text { IFOF, L ILF, L UF }\end{array}$ \\
\hline $\begin{array}{l}\text { Viher et al. } \\
\text { (2016a) }\end{array}$ & SZ: 40 & $34.0(10.40)$ & $\begin{array}{l}\text { DSM-5 SZ symptom } \\
\text { dimension } \\
\text { disorganized speech }\end{array}$ & Whole-brain & & & & \\
\hline
\end{tabular}

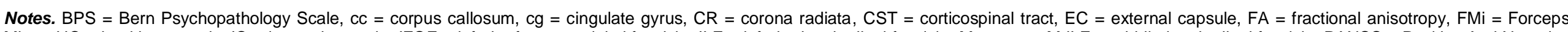

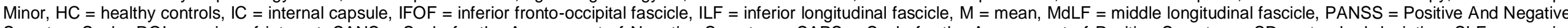

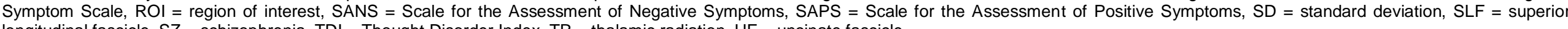
longitudinal fascicle, SZ = schizophrenia, TDI = Thought Disorder Index, TR = thalamic radiation, UF = uncinate fascicle 
Table 3. Correlates of formal thought disorder in schizophrenia: Resting state studies $(n=5)$. Only significant results are presented. If not specified as belonging to the left- $(L)$ or right- $(R)$ hemisphere, the results were found bilaterally.

\begin{tabular}{|c|c|c|c|c|c|c|c|c|c|}
\hline Authors & Patients/HC (n) & Age (M/SD) & FTD assessment & $\begin{array}{l}\text { Imaging } \\
\text { technique }\end{array}$ & Imaging scope & $\begin{array}{l}\text { Increased resting } \\
\text { blood flow }\end{array}$ & $\begin{array}{l}\text { Decreased } \\
\text { resting blood } \\
\text { flow }\end{array}$ & $\begin{array}{l}\text { Positive } \\
\text { correlation }\end{array}$ & $\begin{array}{l}\text { Negative } \\
\text { correlation }\end{array}$ \\
\hline $\begin{array}{l}\text { DeLisi et al. } \\
\text { (1989) }\end{array}$ & $\begin{array}{l}\text { SZ: } 21 \\
\text { HC: } 19\end{array}$ & $\begin{array}{l}28.4(7) \\
31(11)\end{array}$ & $\begin{array}{l}\text { BPRS conceptual } \\
\text { disorganization } \\
\text { item }\end{array}$ & PET & $\begin{array}{l}\text { ROI: TL (STG, } \\
\text { MTG, ITG) }\end{array}$ & & & $\begin{array}{l}\text { L/R-ratio } \\
\mathrm{L} \text { side/whole slice } \\
\text { ratio }\end{array}$ & \\
\hline $\begin{array}{l}\text { Horn et al. } \\
(2009)\end{array}$ & $\begin{array}{l}\text { SZ: } 13 \\
\text { HC: } 13\end{array}$ & $\begin{array}{l}29.6(11.2) \\
26.6(4.6)\end{array}$ & TLC & ASL & Whole-brain & & & $\begin{array}{l}\text { L anterior Ins, L } \\
\text { posterior } \\
\text { STG/ANG, L IFG } \\
\text { pars orbitalis }\end{array}$ & \\
\hline $\begin{array}{l}\text { Liemburg et } \\
\text { al. (2012) }\end{array}$ & $\begin{array}{l}\text { SZ: } 45 \\
\text { HC: } 30\end{array}$ & $\begin{array}{l}34.7(11.4) \\
33.4(10.5)\end{array}$ & $\begin{array}{l}\text { PANSS } \\
\text { conceptual } \\
\text { disorganization } \\
\text { item }\end{array}$ & fMRI & $\begin{array}{l}\text { ROI: STG, HG, } \\
\text { IFG, anterior cg }\end{array}$ & & & & \\
\hline $\begin{array}{l}\text { Sabri et al. } \\
\text { (1997) }\end{array}$ & $\begin{array}{l}\text { SZ: } 24 \\
H C: 20\end{array}$ & $\begin{array}{l}32.3(9.7) \\
54.2(14.1)\end{array}$ & $\begin{array}{l}\text { PANSS } \\
\text { conceptual } \\
\text { disorganization } \\
\text { item before } \\
\text { treatment }\end{array}$ & SPECT & $\begin{array}{l}\text { ROI: FC, anterior } \\
\mathrm{cg}, \mathrm{PC}, \mathrm{TC} \text {, } \\
\text { mesial TC, basal } \\
\text { ganglia, Th }\end{array}$ & & & $\begin{array}{l}\text { FC, anterior cg, } \\
\text { PC, TC, left } \\
\text { mesial TC }\end{array}$ & \\
\hline $\begin{array}{l}\text { Skudlarski et } \\
\text { al. (2010) }\end{array}$ & $\begin{array}{l}\text { SZ: } 27 \\
\text { HC: } 27\end{array}$ & $\begin{array}{l}38(10) \\
39(11)\end{array}$ & TDI & fMRI & Whole-brain & & & $\begin{array}{l}\text { Functional } \\
\text { connectivity: } \\
\text { whole brain, } \\
\text { connection } \\
\text { between Th and L } \\
\text { postcentral } \\
\text { Spatial coherence: } \\
\text { Task Positive } \\
\text { Network (DLPC, } \\
\text { SMA, IPL, MTG, } \\
\text { Ins) }\end{array}$ & $\begin{array}{l}\text { Spatial coherence: } \\
\text { Default Mode } \\
\text { Network-1 } \\
\text { (anterior cg, } \\
\text { posterior } \\
\mathrm{cg} \text { ) }\end{array}$ \\
\hline
\end{tabular}

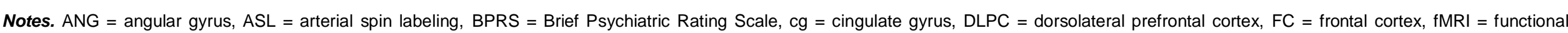

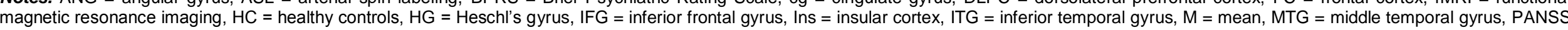

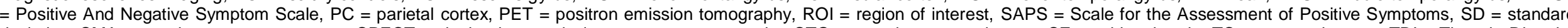

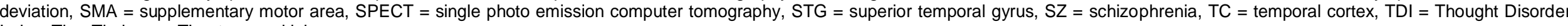
Index, $\mathrm{Th}=$ Thalamus, $\mathrm{TL}=$ temporal lobe 


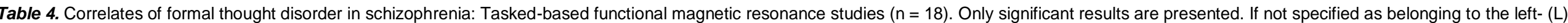
or right- (R) hemisphere, the results were found bilaterally. If the sudy design included three groups (HC, SZ-FTD, SZ-nFTD), only the comparison between SZ-FTD and SZ-FTD Is prese

\begin{tabular}{|c|c|c|c|c|c|c|c|c|c|}
\hline Authors & Patients/HC (n) & Age (M/SD) & FTD assessment & Imaging scope & Task & $\begin{array}{l}\text { Increased } \\
\text { activity }\end{array}$ & $\begin{array}{l}\text { Decreased } \\
\text { activity }\end{array}$ & $\begin{array}{l}\text { Positive } \\
\text { correlation }\end{array}$ & $\begin{array}{l}\text { Negative } \\
\text { correlation }\end{array}$ \\
\hline $\begin{array}{l}\text { Arcuri et al. } \\
\text { (2012) }\end{array}$ & $\begin{array}{l}\text { SZ-FTD: } 9 \\
\text { SZ-nFTD: } 9 \\
\text { HC: } 10\end{array}$ & $\begin{array}{l}33(16) \\
38(21) \\
35(10)\end{array}$ & $\begin{array}{l}\text { SAPS positive } \\
\text { FTD subscale }\end{array}$ & Whole-brain & $\begin{array}{l}\text { Semantic } \\
\text { sentence decision } \\
\text { task }\end{array}$ & $\begin{array}{l}\text { Congruent vs. } \\
\text { incongruent } \\
\text { sentences: SZ- } \\
\text { FTD > SZ-nFTD: } \\
\text { R posterior cg }\end{array}$ & $\begin{array}{l}\text { Congruent vs. } \\
\text { incongruent } \\
\text { sentences: SZ- } \\
\text { FTD < SZ-nFTD: } \\
\text { MFG, anterior cg }\end{array}$ & & L IFG \\
\hline $\begin{array}{l}\text { Assaf et al. } \\
(2006)\end{array}$ & $\begin{array}{l}\text { SZ: } 16 \\
\text { HC: } 16\end{array}$ & $\begin{array}{l}38.6(10.9) \\
37.8(11.4)\end{array}$ & TDI & Whole-brain & $\begin{array}{l}\text { Semantic object } \\
\text { recall task }\end{array}$ & & & Rostral anterior cg & \\
\hline $\begin{array}{l}\text { Chen et al. } \\
\text { (2013) }\end{array}$ & $\begin{array}{l}\text { SZ: } 20 \\
\text { HC: } 20\end{array}$ & $\begin{array}{l}29.4(9.0) \\
30.9(8.4)\end{array}$ & $\begin{array}{l}\text { PANSS } \\
\text { conceptual } \\
\text { disorganization } \\
\text { item }\end{array}$ & $\begin{array}{l}\text { ROI: IFG, } \\
\text { FuG/MTG, Cd }\end{array}$ & $\begin{array}{l}\text { Semantic word } \\
\text { decision task }\end{array}$ & & & $\begin{array}{l}\text { Left IFG pars } \\
\text { triangularis }\end{array}$ & $\begin{array}{l}\text { L Caudate-IFG } \\
\text { connectivity }\end{array}$ \\
\hline $\begin{array}{l}\text { Horn et al. } \\
(2012)\end{array}$ & $\begin{array}{l}\text { SZ: } 16 \\
\text { HC: } 18\end{array}$ & $\begin{array}{l}27.6(7.4) \\
25.6(4)\end{array}$ & TLC & Whole-brain & $\begin{array}{l}\text { Passive semantic } \\
\text { word reading task }\end{array}$ & & & $\begin{array}{l}\text { Reduced spatial } \\
\text { similarity L IFG } \\
\text { pars orbitalis }\end{array}$ & \\
\hline $\begin{array}{l}\text { Jamadar et } \\
\text { al. (2013) }\end{array}$ & $\begin{array}{l}\text { SZ: } 74 \\
\text { HC: } 133 \\
\text { BPD: } 32\end{array}$ & $\begin{array}{l}36.35(1.40) \\
32.48(1.05) \\
36.22(2.1)\end{array}$ & TDI & Whole-brain & $\begin{array}{l}\text { Semantic object } \\
\text { recall task }\end{array}$ & & & & \\
\hline $\begin{array}{l}\text { Kircher et al. } \\
\text { (2001a) }\end{array}$ & $\begin{array}{l}\text { SZ-FTD: } 6 \\
\text { SZ-nFTD: } 6 \\
\text { HC: } 7\end{array}$ & $\begin{array}{l}34.3(11.5) \\
31.2(7.0) \\
34.0(7.9)\end{array}$ & $\begin{array}{l}\text { SAPS positive } \\
\text { FTD subscale }\end{array}$ & Whole-brain & $\begin{array}{l}\text { Semantic } \\
\text { sentence decision } \\
\text { task }\end{array}$ & $\begin{array}{l}\text { Generation vs. } \\
\text { Reading, SZ-FTD } \\
\text { > SZ-nFTD: L } \\
\text { PCun, R Cb, L } \\
\text { Ins, L IFG pars } \\
\text { opercularis, L } \\
\text { MTG }\end{array}$ & $\begin{array}{l}\text { Generation vs. } \\
\text { Reading, SZ-FTD } \\
\text { < SZ-nFTD: R } \\
\text { IFG, R PoG, R } \\
\text { STG, L Cb }\end{array}$ & & \\
\hline $\begin{array}{l}\text { Kircher et al. } \\
\text { (2001b) }\end{array}$ & $\begin{array}{l}\text { SZ-FTD: } 6 \\
\text { HC: } 6\end{array}$ & $\begin{array}{l}34.43(11.5) \\
34.0(7.9)\end{array}$ & $\begin{array}{l}\text { TLI positive FTD } \\
\text { subscale }\end{array}$ & Whole-brain & Free speech & & & Ver, R Cd, PrG & L STG, L MTG \\
\hline $\begin{array}{l}\text { Kircher et al. } \\
(2002)\end{array}$ & $\begin{array}{l}\text { SZ-FTD: } 6 \\
\text { HC: } 6\end{array}$ & $\begin{array}{l}34.43(11.5) \\
34.0(7.9)\end{array}$ & $\begin{array}{l}\text { TLI positive FTD } \\
\text { subscale }\end{array}$ & Whole-brain & Free speech & $\begin{array}{l}\text { Cb, R post- } \\
\text { cerebellar cortex, } \\
\text { FuG, R PCun, R } \\
\text { MTG, R STG }\end{array}$ & L MTG & & \\
\hline $\begin{array}{l}\text { Kircher et al. } \\
(2003)\end{array}$ & $\begin{array}{l}\text { SZ-FTD: } 6 \\
\text { HC: } 6\end{array}$ & $\begin{array}{l}34.43(11.5) \\
34.0(7.9)\end{array}$ & $\begin{array}{l}\text { TLI poverty of } \\
\text { speech item }\end{array}$ & Whole-brain & Free speech & & & $\begin{array}{l}\text { R IPL/SMG, R } \\
\text { MFG, R Cun, L } \\
\text { posterior cg/PCun, } \\
\text { L AG, cc }\end{array}$ & $\begin{array}{l}\text { L Hi/FuG, R FuG, } \\
\text { R MTG, L Cb, L } \\
\text { STG }\end{array}$ \\
\hline
\end{tabular}


Table 4. Continuing

\begin{tabular}{|c|c|c|c|c|c|c|c|c|c|}
\hline Authors & Patients/HC (n) & Age (M/SD) & FTD assessment & Imaging scope & Task & $\begin{array}{l}\text { Increased } \\
\text { activity }\end{array}$ & $\begin{array}{l}\text { Decreased } \\
\text { activity }\end{array}$ & $\begin{array}{l}\text { Positive } \\
\text { correlation }\end{array}$ & $\begin{array}{l}\text { Negative } \\
\text { correlation }\end{array}$ \\
\hline $\begin{array}{l}\text { Kircher et al. } \\
(2008)\end{array}$ & $\begin{array}{l}\text { SZ: } 12 \\
\text { HC: } 12\end{array}$ & $\begin{array}{l}26.83(11.6) \\
26.50(7.26)\end{array}$ & $\begin{array}{l}\text { Composite score } \\
\text { of SAPS positive } \\
\text { FTD subscale and } \\
\text { SANS poverty of } \\
\text { content of speech } \\
\text { item }\end{array}$ & Whole-brain & $\begin{array}{l}\text { Free verbal } \\
\text { association task, } \\
\text { semantic and } \\
\text { phonological } \\
\text { verbal fluency } \\
\text { tasks }\end{array}$ & & & & $\begin{array}{l}\text { Free verbal } \\
\text { association versus } \\
\text { Reading: R ITG, R } \\
\text { LgG }\end{array}$ \\
\hline $\begin{array}{l}\text { Kuperberg et } \\
\text { al. (2007) }\end{array}$ & $\begin{array}{l}\text { SZ: } 17 \\
\text { HC: } 15\end{array}$ & $\begin{array}{l}45.1(9.55) \\
41.6(11.4)\end{array}$ & $\begin{array}{l}\text { PANSS } \\
\text { conceptual } \\
\text { disorganization } \\
\text { item }\end{array}$ & $\begin{array}{l}\text { ROI: L IFG (pars } \\
\text { triangularis, pars } \\
\text { orbitalis), OFG, L } \\
\text { lateral TL (STG, } \\
\text { STS, MTG), } \\
\text { temporal FuG, L } \\
\text { Hi-Amygdala- } \\
\text { complex }\end{array}$ & $\begin{array}{l}\text { Semantic word } \\
\text { decision task }\end{array}$ & & & & $\begin{array}{l}\text { Indirectly related } \\
\text { vs. unrelated word } \\
\text { pairs: Temporal } \\
\text { FuG/MTG }\end{array}$ \\
\hline $\begin{array}{l}\text { Matsumoto et } \\
\text { al. (2013) }\end{array}$ & $\begin{array}{l}\text { SZ-FTD: } 6 \\
\text { HC: } 6\end{array}$ & $\begin{array}{l}34.3(11.5) \\
34.0(7.9)\end{array}$ & $\begin{array}{l}\text { SAPS positive } \\
\text { FTD subscale }\end{array}$ & Whole-brain & Free speech & & $\begin{array}{l}\mathrm{LTmP}, \mathrm{R} \\
\text { retrosplenial cg / } \\
\text { AG }\end{array}$ & & \\
\hline $\begin{array}{l}\text { McGuire et } \\
\text { al. (1998) }\end{array}$ & SZ-FTD: 6 & $34(26-45)$ & $\begin{array}{l}\text { TLI positive FTD } \\
\text { subscale }\end{array}$ & Whole-brain & Free speech & & & $\begin{array}{l}\text { R Cd, L PHG, R } \\
\text { FuG/MTG }\end{array}$ & $\begin{array}{l}\text { L STG, IFG pars } \\
\text { orbitalis, L Ins, } \\
\text { anterior/posterior } \\
\text { cg, R MFG }\end{array}$ \\
\hline $\begin{array}{l}\text { Ragland et } \\
\text { al. (2008) }\end{array}$ & $\begin{array}{l}\text { SZ: } 13 \\
\text { HC: } 14\end{array}$ & $\begin{array}{l}36.2(6.9) \\
34.3(9.2)\end{array}$ & CDI & Whole-brain & $\begin{array}{l}\text { Semantic word } \\
\text { generation task } \\
\text { (OS = over- } \\
\text { learned fluency, } \\
\text { SC = semantic } \\
\text { category fluency) }\end{array}$ & & & $\begin{array}{l}\text { OS Switch versus } \\
\text { OS No Switch: L } \\
\text { LgG, R FuG, } \\
\text { SC Switch versus } \\
\text { SC No Switch: L } \\
\text { SPG }\end{array}$ & $\begin{array}{l}\text { SC versus } \\
\text { baseline: } \mathrm{R} \\
\text { anterior cg, R Cun } \\
\text { SC versus OS: R } \\
\text { SFG }\end{array}$ \\
\hline $\begin{array}{l}\text { Rapp et al. } \\
(2013)\end{array}$ & $\begin{array}{l}\text { SZ: } 15 \\
\text { HC: } 15\end{array}$ & $\begin{array}{l}28.1 \\
32.9\end{array}$ & $\begin{array}{l}\text { SAPS positive } \\
\text { FTD subscale }\end{array}$ & Whole-brain & $\begin{array}{l}\text { Silent reading of } \\
\text { ironic and literal } \\
\text { text vignettes }\end{array}$ & & & $\begin{array}{l}\text { L posterior cg, L } \\
\text { Th, R STG }\end{array}$ & \\
\hline $\begin{array}{l}\text { van Veelen } \\
\text { et al. (2011) }\end{array}$ & $\begin{array}{l}\text { SZ: } 35 \\
\text { HC: } 43\end{array}$ & $\begin{array}{l}24.18(4.24) \\
24.08(4.65)\end{array}$ & $\begin{array}{l}\text { PANSS } \\
\text { conceptual } \\
\text { disorganization } \\
\text { item }\end{array}$ & $\begin{array}{l}\text { ROI: STG, IFG } \\
\text { pars triangularis } \\
\text { and opercularis }\end{array}$ & $\begin{array}{l}\text { Semantic } \\
\text { decision, verb } \\
\text { generation, } \\
\text { antonym } \\
\text { generation tasks }\end{array}$ & & & & \\
\hline $\begin{array}{l}\text { Weinstein et } \\
\text { al. (2006) }\end{array}$ & $\begin{array}{l}\text { SZ: } 12 \\
\text { HC: } 11\end{array}$ & $\begin{array}{l}35.9(12.6) \\
34(12)\end{array}$ & TLI & Whole-brain & $\begin{array}{l}\text { Receptive } \\
\text { language task }\end{array}$ & & & $\begin{array}{l}\text { L posterior STS, L } \\
\text { MTG }\end{array}$ & \\
\hline $\begin{array}{l}\text { Weinstein et } \\
\text { al. (2007) }\end{array}$ & SZ: 12 & $35.9(12.6)$ & TLI & L PT & $\begin{array}{l}\text { Receptive } \\
\text { language task }\end{array}$ & & & $\begin{array}{l}\mathrm{L} \text { middle-posterior } \\
\text { STG and MTG }\end{array}$ & \\
\hline
\end{tabular}




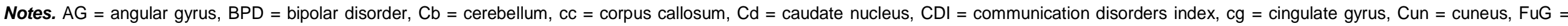
fusiform gyrus, $\mathrm{HC}=$ healthy controls, $\mathrm{Hi}=$ Hippocampus, IFG = inferior frontal gyrus, Ins = insular cortex, IPL = inferior parietal lobule, ITG = inferior temporal gyrus, $L g G=$ lingual gyrus, $M=$ mean, $M F G$

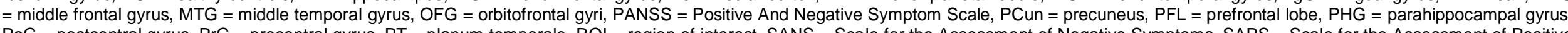

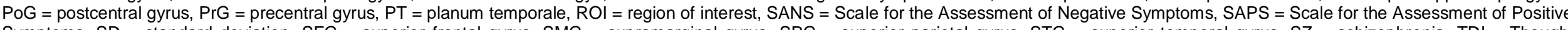

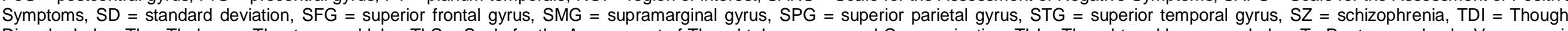

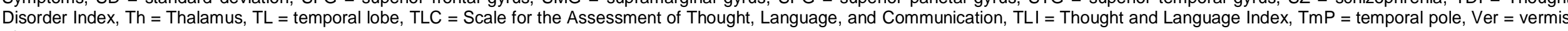
of cerebellum 
Table 5. Quality evaluation of the included studies, considering statistical power (criterion 1) and the multidimensional assessment of FTD (criterion 2)

\begin{tabular}{|c|c|c|c|}
\hline Study & Criterion 1 & Criterion 2 & Quality level \\
\hline Anderson et al. (2002) & 2 & 1 & C \\
\hline Arcuri et al. (2012) & 1 & 1 & C \\
\hline Arnedo et al. (2015) & 3 & 2 & $A$ \\
\hline Asami et al. (2013) & 2 & 1 & $\mathrm{C}$ \\
\hline Assaf et al. (2006) & 2 & 1 & C \\
\hline Barta et al. (1997) & 2 & 1 & C \\
\hline Bijanki et al. (2015) & 3 & 1 & $\mathrm{~B}$ \\
\hline Bopp et al. (2016) & 3 & 1 & B \\
\hline Chen et al. (2013) & 2 & 1 & $\mathrm{C}$ \\
\hline DeLisi et al. (1989) & 2 & 1 & C \\
\hline DeLisi et al. (1994) & 3 & 1 & $\mathrm{~B}$ \\
\hline DeLisi et al. (2005) & 1 & 1 & C \\
\hline Dieci et al. (1998) & 2 & 1 & C \\
\hline Elfaki et al. (2016) & 3 & 1 & $\mathrm{~B}$ \\
\hline Fukuzako et al. (1996) & 2 & 1 & C \\
\hline Holinger et al. (1999) & 1 & 1 & $\mathrm{C}$ \\
\hline Horn et al. (2009) & 1 & 1 & C \\
\hline Horn et al. (2010) & 2 & 1 & $\mathrm{C}$ \\
\hline Horn et al. (2012) & 2 & 1 & C \\
\hline Jamadar et al. (2013) & 3 & 1 & $\mathrm{~B}$ \\
\hline Kircher et al. (2001a) & 1 & 1 & C \\
\hline Kircher et al. (2001b) & 1 & 1 & C \\
\hline Kircher et al. (2002) & 1 & 1 & C \\
\hline Kircher et al. (2003) & 1 & 1 & $\mathrm{C}$ \\
\hline Kicher et al. (2008) & 1 & 1 & C \\
\hline Kühn et al. (2012) & 2 & 1 & C \\
\hline Kuperberg et al. (2007) & 2 & 1 & $\mathrm{C}$ \\
\hline Levitt et al. (1999) & 2 & 1 & C \\
\hline Liemburg et al. (2012) & 3 & 1 & $\mathrm{~B}$ \\
\hline Marsh et al. (1997) & 3 & 1 & $\mathrm{~B}$ \\
\hline Matsumoto et al. (2013) & 1 & 1 & C \\
\hline McGuire et al. (1998) & 1 & 1 & C \\
\hline Meisenzahl et al. (2004) & 3 & 1 & $\mathrm{~B}$ \\
\hline Menon et al. (1995) & 2 & 1 & C \\
\hline Nakamura et al. (2008) & 2 & 1 & C \\
\hline Nestor et al. (1998) & 2 & 1 & $\mathrm{C}$ \\
\hline Niznikiewicz et al. (2000) & 2 & 1 & C \\
\hline Palaniyappan et al. (2015) & 2 & 2 & B \\
\hline Petty et al. (1995) & 1 & 1 & $\mathrm{C}$ \\
\hline Portas et al. (1998) & 2 & 1 & C \\
\hline Ragland et al. (2008) & 1 & 1 & C \\
\hline Rajarethinam et al. (2000) & 2 & 1 & $\mathrm{C}$ \\
\hline
\end{tabular}


Table 5. Continuing

\begin{tabular}{lccc}
\hline Study & Criterion 1 & Criterion 2 & Quality level \\
\hline Rajarethinam et al. (2001) & 2 & 1 & $\mathrm{C}$ \\
Rapp et al. (2013) & 2 & 1 & $\mathrm{C}$ \\
Rossi et al. (1994) & 2 & 1 & $\mathrm{C}$ \\
Sabri et al. (1997) & 2 & 1 & $\mathrm{C}$ \\
Sallet et al. (2003) & 2 & 1 & $\mathrm{C}$ \\
Sans-Sansa et al. (2013) & 2 & 2 & $\mathrm{~B}$ \\
Shapleske et al. (2001) & 3 & 1 & $\mathrm{~B}$ \\
Skundlarski et al. (2010) & 2 & 1 & $\mathrm{C}$ \\
Shenton et al. (1991) & 1 & 1 & $\mathrm{C}$ \\
Shenton et al. (1992) & 2 & 1 & $\mathrm{C}$ \\
Subotnik et al. (2003) & 2 & 1 & $\mathrm{C}$ \\
Takahashi et al. (2001) & 2 & 1 & $\mathrm{C}$ \\
Van Veelen et al. (2011) & 3 & 1 & $\mathrm{~B}$ \\
Viher et al. (2016a) & 3 & 1 & $\mathrm{~B}$ \\
Viher et al. (2016b) & 3 & 2 & $\mathrm{~A}$ \\
Vita et al. (1995) & 2 & 1 & $\mathrm{C}$ \\
Weinstein et al. (2006) & 1 & 1 & $\mathrm{C}$ \\
Weinstein et al. (2007) & 1 & 1 & $\mathrm{C}$ \\
Yamasue et al. (2004) & 2 & 1 & $\mathrm{C}$ \\
\hline
\end{tabular}

Notes. Criterion 1 (sample size): $1=<15$ participants/group, $2=15-30$ participants/group, $3=>30$ participants per group. Criterion 2 (multidimensional assessment of FTD): 1 = unidimensional, 2 = multidimensional. Quality level: $\mathrm{A}$ $($ sum score 5$)=$ good, $B($ sum score 4$)=$ medium, $C($ sum score 3 or 2$)=$ low. 